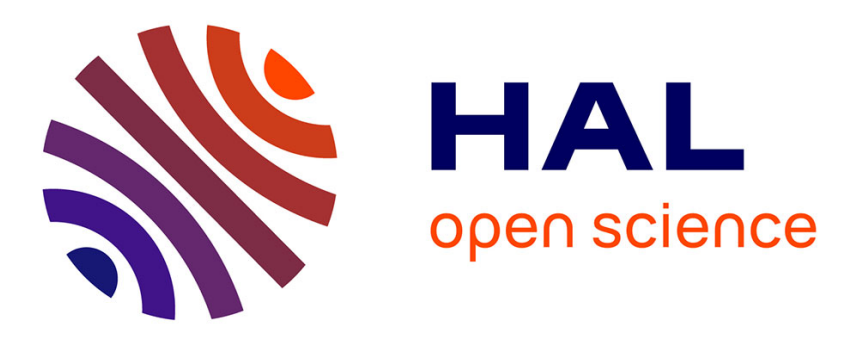

\title{
The effect of polystyrene sodium sulfonate grafting on polyethylene terephthalate artificial ligaments on in vitro mineralisation and in vivo bone tissue integration
}

Cédryck Vaquette, Véronique Viateau, Sandra Guerard, Fani Anagnostou, Mathieu Manaserro, David G. Castner, Véronique Migonney

\section{To cite this version:}

Cédryck Vaquette, Véronique Viateau, Sandra Guerard, Fani Anagnostou, Mathieu Manaserro, et al.. The effect of polystyrene sodium sulfonate grafting on polyethylene terephthalate artificial ligaments on in vitro mineralisation and in vivo bone tissue integration. Biomaterials, 2013, 34 (29), pp.70487063. 10.1016/j.biomaterials.2013.05.058 . hal-00870666

\section{HAL Id: hal-00870666 https://hal.science/hal-00870666}

Submitted on 16 Oct 2013

HAL is a multi-disciplinary open access archive for the deposit and dissemination of scientific research documents, whether they are published or not. The documents may come from teaching and research institutions in France or abroad, or from public or private research centers.
L'archive ouverte pluridisciplinaire HAL, est destinée au dépôt et à la diffusion de documents scientifiques de niveau recherche, publiés ou non, émanant des établissements d'enseignement et de recherche français ou étrangers, des laboratoires publics ou privés. 


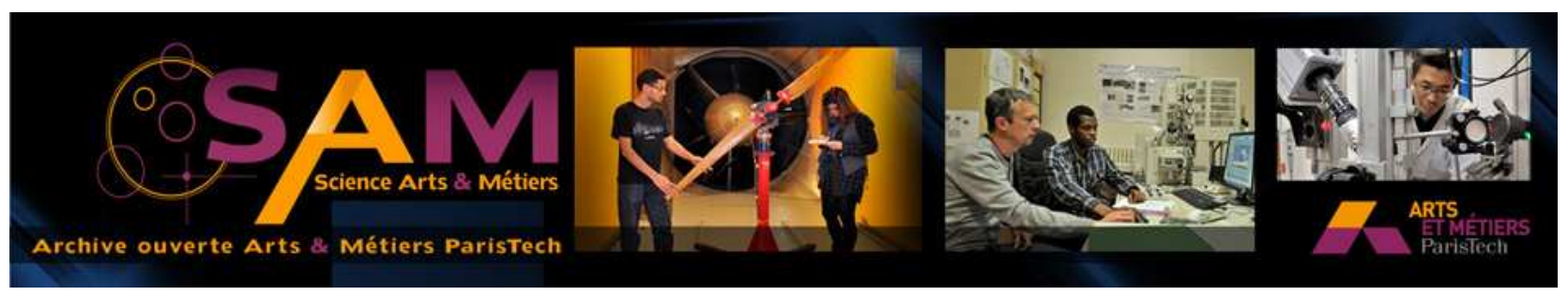

\section{Science Arts \& Métiers (SAM)}

is an open access repository that collects the work of Arts et Métiers ParisTech researchers and makes it freely available over the web where possible.

This is an author-deposited version published in: http://sam.ensam.eu

Handle ID: .http://hdl.handle.net/10985/7377

\section{To cite this version :}

Cédryck VAQUETTE, Véronique VIATEAU, Sandra GUERARD, Fani ANAGNOSTOU, Mathieu MANASSERO, David G. CASTNER, Véronique MIGONNEY - The effect of polystyrene sodium sulfonate grafting on polyethylene terephthalate artificial ligaments on in vitro mineralisation and in vivo bone tissue integration - The effect of polystyrene sodium sulfonate grafting on polyethylene terephthalate artificial ligaments on in vitro mineralisation and in vivo bone tissue integration - Vol. $34, n^{\circ} 29$, p.7048-7063 - 2013 


\title{
The effect of polystyrene sodium sulfonate grafting on polyethylene terephthalate artificial ligaments on in vitro mineralisation and in vivo bone tissue integration
}

\author{
Cédryck Vaquette $^{\mathrm{a}, *}$, Véronique Viateau ${ }^{\mathrm{b}, \mathrm{c}}$, Sandra Guérard ${ }^{\mathrm{d}}$, Fani Anagnostou ${ }^{\mathrm{c}, \mathrm{e}}$, \\ Mathieu Manassero ${ }^{\mathrm{b}, \mathrm{c}}$, David G. Castner ${ }^{\mathrm{f}}$, Véronique Migonney ${ }^{\mathrm{g}, * *}$ \\ ${ }^{a}$ Institute of Health and Biomedical Innovation, Queensland University of Technology, 60 Musk avenue, Kelvin Grove, QLD 4278, Australia \\ ${ }^{\mathrm{b}}$ Université Paris Est, Ecole Nationale Vétérinaire d'Alfort, 7 avenue du général de Gaulle, 94704 Maisons Alfort Cedex, France \\ ${ }^{\mathrm{c}}$ Laboratoire de Bioingénierie et Biomécanique Ostéoarticulaire, UMR-CNRS 7052, 10 avenue de Verdun, Paris 75 010, France \\ ${ }^{\mathrm{d}}$ Arts et Métiers ParisTech, LBM, 151 bd de l'hôpital, 75013 Paris, France \\ e Unité de Formation et Recherche d'Odontologie, Hôpital la Pitié Salpêtrière, AP-HP, Université Paris 7-Diderot, Paris, France \\ ${ }^{\mathrm{f}}$ National ESCA and Surface Analysis Center for Biomedical Problems (NESAC/Bio), Departments of Bioengineering and Chemical Engineering, Box 351653, \\ University of Washington, Seattle, WA, USA \\ ${ }^{\mathrm{g}}$ Laboratoire de Biomatériaux et Polymères de Spécialité (LBPS), Laboratoire Chimie, Structures, Propriétés de Biomatériaux et d'Agents Thérapeutiques \\ (CSPBAT), UMR CNRS 7244, Université Paris 13 Sorbonne Paris Cité, 99 Avenue J.B. Clément, Villetaneuse 93 430, France
}

\begin{abstract}
A B S T R A C T
This study investigates the impact of polystyrene sodium sulfonate (PolyNaSS) grafting onto the osseointegration of a polyethylene terephthalate artificial ligament (Ligament Advanced Reinforcement System, LARS ${ }^{\mathrm{TM}}$ ) used for Anterior Cruciate Ligament (ACL). The performance of grafted and non-grafted ligaments was assessed in vitro by culturing human osteoblasts under osteogenic induction and this demonstrated that the surface modification was capable of up-regulating the secretion of ALP and induced higher level of mineralisation as measured 6 weeks post-seeding by Micro-Computed Tomography. Grafted and non-grafted LARS ${ }^{\mathrm{TM}}$ were subsequently implanted in an ovine model for ACL reconstruction and the ligament-to-bone interface was evaluated by histology and biomechanical testings 3 and 12 months post-implantation. The grafted ligaments exhibited more frequent direct ligament-tobone contact and bone formation in the core of the ligament at the later time point than the nongrafted specimens, the grafting also significantly reduced the fibrous encapsulation of the ligament 12 months post-implantation. However, this improved osseo-integration was not translated into a significant increase in the biomechanical pull-out loads. These results provide evidences that PolyNaSS grafting improved the osseo-integration of the artificial ligament within the bone tunnels. This might positively influence the outcome of the surgical reconstructions, as higher ligament stability is believed to limit micro-movement and therefore permits earlier and enhanced healing.
\end{abstract}

\section{Introduction}

Anterior cruciate ligament (ACL) rupture is the most common sport injury and due to its poor healing capacity [1,2], surgical treatments are often required for restoring the function of the knee. In the early eighties synthetic ligaments became increasingly popular and were believed to overcome the limitations associated with

\footnotetext{
* Corresponding author. Tel.: +617 313862 99; fax: +617 31386028 .

** Corresponding author. Tel.: +331 494033 52; fax: +331 49402036 . E-mail addresses: cedryck.vaquette@qut.edu.au, vaquettc@yahoo.fr (C. Vaquette), veronique.migonney@univ-paris13.fr (V. Migonney).
}

conventional grafts (such as donor site morbidity, pain, availability [3]). This enthusiasm was abruptly stopped when the long term behaviour and safety of these implants were assessed. Indeed, despite acceptable short term stability, most of the artificial ligaments experienced excessive plastic deformation leading to a significant increase in knee laxity [4,5]. Moreover, incomplete and unpredictable tissue ingrowth resulted in major structural changes, high incidence of rupture and synovitis. Most of these artificial prostheses were retrieved from the market or their utilisation was limited to selected cases. Since then, autologous tissues such as Bone Patellar Tendon Bone (BPTB) [6] and Semitendinosus and Gracilis Tendon (SGT) [7] are the most commonly used grafts for ACL 
reconstruction providing excellent clinical results and subjective high satisfaction rates from 80 to $90 \%$ [8,9]. Long term follow-ups have been well documented and have shown that despite a high rate of post-traumatic osteoarthritis [7,9,10], ACL reconstruction with autologous tissue grafts displayed excellent functional recovery over more than 10 years $[8,10]$.

These above mentioned techniques take advantage of the use of autologous natural tissue which facilitates the implant tissueintegration, nevertheless they present major inconveniences related to tissue harvesting and therefore induced site morbidity, pain, moderate to long recovery periods before resuming physical exercise and professional activity. Another disadvantage reported in the literature originates from the larger diameter of the bone tunnels (10 mm compared to 4-6 $\mathrm{mm}$ for synthetic ligament [11]) surgically created for ACL reconstruction using BPTB or SGT which results in a more difficult and complex re-intervention if required.

Still, the alternative proposed by artificial ligaments, when well designed and safe to use, presents many advantages such as reduced time of surgical procedure (no tissue harvesting is required), elimination of post-surgical complications associated to tissue harvesting (donor site necrosis, pain reduced tissue trauma), reduced recovery period before returning to normal physical activity and readily available artificial ligaments for both patients and surgeons. Despite these significant advantages, synthetic ligaments suffer from the reputation gained in the early eighties. Indeed, there are non-negligible concerns regarding the long term performances of theses implants such as excessive creep and inappropriate fatigue behaviour leading to mechanical failure, which have limited their utilisation in the past. Today, major advances in polymer quality, weaving and braiding technologies as well as more reproducible surgical techniques have resulted to the development of a new generation of synthetic ligaments such as the LARSTM ligament (Ligament Advanced Reinforcement System). Recent short and mid-term follow-up studies have demonstrated positive clinical outcomes [12-15], with only a few cases reporting synovitis and ruptures [16,17]. Synthetic ligament failures are often caused by the lack of integration of the ligament in the bone tunnels along with non-optimal cell infiltration and organisation within the ligament compartment [17]. Therefore another step forward is the improvement of the artificial ligament bio-integration which is believed to play a significant role in enhancing the long term performances of these synthetic implants [18]. For this purpose several strategies have been proposed and these are mainly based onto the surface modification of the polymer. Grafting synthetic polymer, biopolymer or peptides onto implant surfaces have demonstrated to affect significantly cell behaviour both in vitro and in vivo. To this end, Ciobanu et al. have developed a radical graft polymerisation of polystyrene sodium sulfonate (PolyNASS) onto poly(ethylene terephthalate) (PET) [19] in order to enhance the interaction of the LARS ligament with relevant cells, that is, fibroblasts [20]. This method proved very efficient at accelerating fibroblasts adhesion along with achieving enhanced control over the fibroblast morphology and alignment onto the PolyNaSS grafted fibres [20]. This grafting method was further applied to examine the interaction of the grafting material when osteoblast-like cells were inoculated onto other surfaces such as titanium. Several studies showed that the presence of the bioactive PolyNaSS polymer layer significantly enhanced the adhesion strength of an osteoblastic-like cell line [21-23] and up-regulated the secretion of alkaline phosphatase ALP [21,22] indicated that cells were committed to osteodifferentiation when seeded onto the grafting material. This effect was also translated in vivo as the PolyNaSS surface modification supported earlier bone formation than the non-grafted titanium disc in a rabbit femoral condyle defect [24].

These findings were reported for two-dimensional structures mostly utilised for dental applications, so they could not provide insight into the interaction of primary human osteoblasts in the context of a braided three-dimensional prosthesis for orthopaedic application. This present study aims to investigate the performance of bioactive grafted PET LARS ${ }^{\mathrm{TM}}$ ligaments onto human osteoblasts both in vitro and to subsequently evaluate their osseo-integration in vivo using an ovine relevant orthopaedic model.

\section{Materials and methods}

2.1. PolyNaSS bioactive polymer grafting and characterisation

The PET synthetic ligaments were provided by the LARS SA (Arc sur Tille, France) and consisted of 44 strands of fibres made of polyethylene terephtalate (PET). The two segments which are to be positioned in the bone tunnels are composed of longitudinal fibres (25- $\mu \mathrm{m}$ diameter circular PET fibres) bound together by a transverse PET knitted structure (25- $\mu$ m diameter, polygonal PET fibres) while the intra-articular segment is composed of parallel, $25-\mu \mathrm{m}$ diameter circular longitudinal fibres. The average value of its ultimate tensile strength is $2500 \mathrm{~N}$. Prior to the grafting process, the ligaments were washed sequentially in tetrahydrofuran (THF), at ambient temperature, for $15 \mathrm{~min}$, then immersed in ultra pure water for $15 \mathrm{~min}$. Thereafter, the ligaments were placed in a boiling $5 \% \mathrm{Na}_{2} \mathrm{CO}_{3}$ solution for $15 \mathrm{~min}$. The samples were then dried under vacuum at $65^{\circ} \mathrm{C}$ for $30 \mathrm{~min}$.

The grafting procedure was performed as reported by Ciobanu et al. [19] and is schematically illustrated in Fig. 1: Ozonation treatment was carried out in an ozone generator (BMT 802). Optimal ozonation conditions were found to be the following: room temperature, $0.6 \mathrm{~L} / \mathrm{min}$ oxygen, and $100 \mathrm{~V}$. Under these conditions it was assumed that the ozone concentration in aqueous solution can reach $3 \%(\mathrm{v} / \mathrm{v})$. The PET fabrics samples were placed in $70 \mathrm{~mL}$ of ultra pure water and exposed to the ozone flow for $30 \mathrm{~min}$. Immediately after ozonation, each ligament was fully immersed into a polystyrene sodium sulfonate (PolyNaSS) aqueous solution (15\% $\mathrm{wt} / \mathrm{vol}$ ), under stirring and argon atmosphere. The grafting temperature was kept constant at $70{ }^{\circ} \mathrm{C}$ and the polymerisation process took place over $1 \mathrm{~h}$. After grafting the samples were extensively washed with ultra pure water and PBS for $1 \mathrm{~h}$ and dried before sterilization by beta irradiation of $25 \mathrm{kGy}$ (Ionisation, France). The

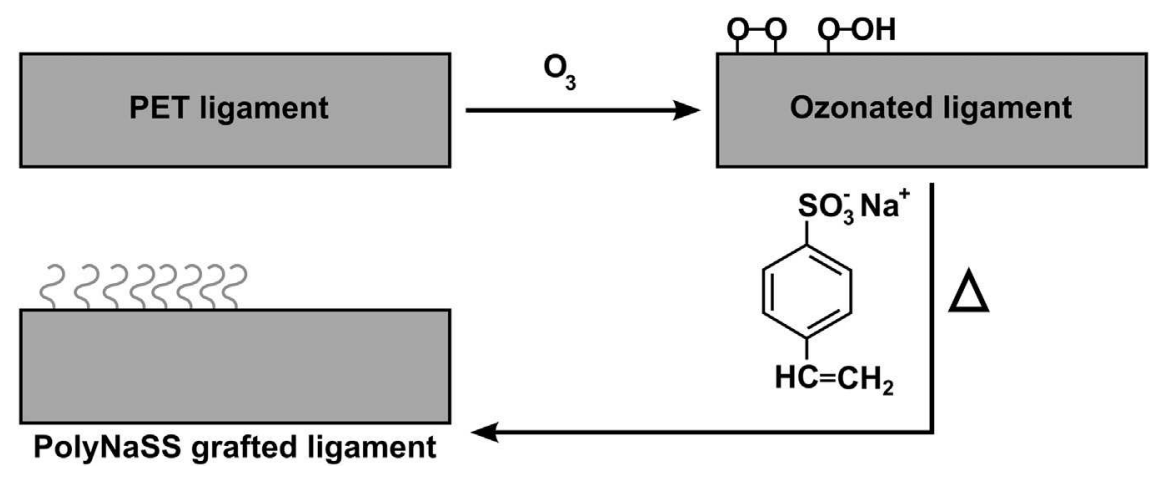

Fig. 1. Schematic description of the grafting process. 
stable and covalent grafting of the PolyNaSS material did not alter the mechanical properties of the synthetic ligament (unpublished data).

The characterisation of the grafting was performed by XPS analysis. XPS data were acquired on a Surface Science Instruments S-probe spectrometer using a monochromatised Al $\mathrm{K} \alpha \mathrm{X}$-ray source. X-ray spot size for these acquisitions was approximately $800 \mu \mathrm{m} \times 800 \mu \mathrm{m}$. Pressure in the analytical chamber during spectral acquisition was less than $5 \times 10^{-9}$ torr. Pass energy for survey spectra and detailed scans of sulphur and sodium (for composition) was $150 \mathrm{eV}$ and pass energy for high resolution C1s (HRC) scans was $50 \mathrm{eV}$. The take-off angle (the angle between the sample normal and the input axis of the energy analyser) was $55^{\circ}$, (which corresponds to $\cong 50 \AA$ A sampling depth). Three spots per sample were analysed from two samples (six analyses per sample type) to determine average composition and standard deviations.

The Service Physics ESCAVB Graphics Viewer program was used to determine peak areas, to calculate the elemental compositions from peak areas and to peak fit the high resolution spectra. The binding energy scale of the high-resolution spectra was calibrated by assigning the hydrocarbon peak in the C1s high-resolution spectrum a binding energy of $285.0 \mathrm{eV}$.

A colorimetric method using toluidine blue was utilised for investigating the distribution of the grafting throughout the artificial ligament. For this purpose, $50 \mathrm{~mL}$ of a $0.5 \mathrm{~mm}$ toluidine blue (TB) aqueous solution was prepared, and $0.2 \mathrm{~mL}$ of a buffer solution of 2-amino 2-methyl propanol was added to adjust the $\mathrm{pH}$ to 10 . The grafted and non-grafted artificial ligament were sectioned in several pieces and immersed in $6 \mathrm{~mL}$ of the TB solution at $30^{\circ} \mathrm{C}$ for $6 \mathrm{~h}$. Non-complexed TB molecules were removed by washing the samples in a $0.5 \mathrm{~mm} \mathrm{NaOH}$ solution for $30 \mathrm{~min}$. Images of the cross-sectional portion of the LARS ligament which would be inserted in the bone tunnels (referred herein as the bone compartment) were taken.

\subsection{In vitro study}

\subsubsection{Cell isolation and culture}

Human mandibular osteoblasts were kindly provided by Prof Ivanovski (School of Dentistry and Oral Health, Griffith University, South Port, Australia). Following institutional ethics approval, the cells were extracted from one patient undergoing dental surgery. Portions of alveolar bone removed during tooth extraction were treated with $0.05 \%$ trypsin $\left(37^{\circ} \mathrm{C}, 30 \mathrm{~min}\right)$ followed by $0.2 \%$ collagenase $\left(37^{\circ} \mathrm{C}\right.$, $30 \mathrm{~min}$ ), then washed three times with phosphate-buffered saline before the bone was chipped into small segments, covered with media (DMEM high glucose, invitrogen) and incubated at $37{ }^{\circ} \mathrm{C}$ with $5 \%$. Outgrowth of osteoblasts was observed after 5-7 days. Cells were expanded and used at the fifth passage (P5).

\subsubsection{Synthetic ligament seeding}

Portions of the bone compartment were sectioned under sterile conditions into $7 \mathrm{~mm}$ long and $5 \mathrm{~mm}$ diameter cylinders and were placed in a 24-well plate. The grafted and non-grafted ligaments, referred as GL and NGL, were seeded with 100,000 osteoblasts suspended in $50 \mu \mathrm{L}$ of media. The cellularised solution immediately infiltrated the structures and $25 \mu \mathrm{L}$ of media were added on the top of the structure every $30 \mathrm{~min}$ in order to minimise adverse events induced by media evaporation. After $4 \mathrm{~h}$ of incubation at $37^{\circ} \mathrm{C}$, the wells were filled with $1 \mathrm{~mL}$ of media. The structures were cultured in osteogenic media $(50 \mu \mathrm{g} / \mathrm{mL}$ ascorbate-2phosphate, 10 mм $\beta$-glycerophosphate, $0.1 \mu \mathrm{m}$ dexamethasone) for 6 weeks with a bi-weekly media change.

\subsubsection{Alkaline phosphatase activity and DNA content}

Osteoblast proliferation was measured by picogreen assay at $24 \mathrm{~h}, 2,4$ and 6 weeks post-seeding $(n=3)$. At 2,4 and 6 weeks post-seeding, ALP activity $(n=3)$ was measured in the cell culture media after a $24 \mathrm{~h}$ release period according to the following protocol: the samples were placed in a new 24 well-plate and rinsed in DMEM without phenol red three times. $1 \mathrm{~mL}$ of DMEM without phenol red was added in each well and the plates were placed back in the incubator for precisely 24 h. ALP activity was measured according to the SigmaFAST ${ }^{\text {тм }}$ kit. $100 \mu \mathrm{L}$ of pNitrophenyl phosphate in Tris-base buffer were added to $100 \mu \mathrm{L}$ of the culture media in a 96-well plate. This was performed in triplicate and these wells were further incubated for $24 \mathrm{~h}$ in the incubator at $37{ }^{\circ} \mathrm{C}$. At the end of the second incubation period the 96 well-plate was brought back to ambient temperature $\left(20^{\circ} \mathrm{C}\right)$ for $5 \mathrm{~min}$ and the absorbance was read at $405 \mathrm{~nm}$ using a plate reader (Benchmark PlusTM microplate spectrophotometer, BIO RAD).

For cellular DNA content analysis, the remaining media was removed from the wells and the samples frozen at $-80{ }^{\circ} \mathrm{C}$ for at least $48 \mathrm{~h}$. The samples were transferred into $2 \mathrm{~mL}$ Eppendorf and $1.5 \mathrm{~mL}$ of a $0.5 \mathrm{mg} / \mathrm{mL}$ proteinase $\mathrm{K}$ solution (Invitrogen) in phosphate buffered EDTA (PBE) at $60^{\circ} \mathrm{C}$ was utilised for disrupting the cell membrane and the extracellular matrix for $24 \mathrm{~h}$. This DNA-containing solution was thereafter diluted at a ratio of $1 / 30$ in PBE and $100 \mu \mathrm{L}$ of this diluted solution was aliquoted into black 96-well plates and $100 \mu \mathrm{L}$ of PicoGreen (P11496, Invitrogen) working solution was added according to the manufacturer's instructions and performed in triplicate. After 5 min incubation in the dark, the fluorescence (excitation $485 \mathrm{~nm}$, emission $520 \mathrm{~nm}$ ) was measured using a fluorescence plate reader (Fluostrar Optima). A standard curve was also constructed using known concentrations of $\lambda$ DNA (Picogreen Assay kit, Invitrogen) where the standards ranged from
$10 \mathrm{ng} / \mathrm{mL}$ to $1 \mu \mathrm{g} / \mathrm{mL} \lambda$ DNA and was used to calculate the final DNA content of the sample. Alkaline phosphatase activity was normalised by the DNA content of the corresponding sample.

\subsubsection{Alizarin red $S$ staining}

A $1 \%$ alizarin Red S solution (Sigma-Aldrich, Australia) was used to assess the deposition of mineralised matrix $(n=3)$. In brief, the structures were rinsed twice in PBS and then fixed for $10 \mathrm{~min}$ in cold methanol. After rinsing in Millipore $\mathrm{H}_{2} \mathrm{O}, 1 \mathrm{~mL}$ of alizarin solution was added and incubated for $10 \mathrm{~min}$ at room temperature. The unfixed dye was removed by gently rinsing the stained structures with Millipore $\mathrm{H}_{2} \mathrm{O}$ until a clear solution was obtained (generally after 10 rinses). The samples were air dried overnight, examined and photographed from the surface but also from the longitudinal cross-section.

\subsubsection{Scanning electron microscopy (SEM) and confocal laser scanning microscopy} (CLSM)

The morphology of osteoblasts adhered onto the surface of the artificial ligament was also imaged by SEM and CLSM. For the SEM analysis the samples were fixed in a $3 \%$ glutaraldehyde solution in $0.1 \mathrm{~m}$ cacodylate buffer ( $\mathrm{pH} 7.4$ ), then dehydrated in a concentration gradient of ethanol and finally carbon coated. At 6 weeks post seeding mineralised nodules on the samples were analysed by Energy Dispersive X-ray Spectroscopy (EDXS) using a FEI Quanta 200 SEM operating at $10 \mathrm{kV}$ and at a $10 \mathrm{~mm}$ working distance. The atomic ratio between calcium and phosphorus $(\mathrm{Ca} / \mathrm{P})$ was calculated from at least 5 different nodules. For CLSM, the artificial ligaments were fixed in a $4 \%$ paraformaldehyde solution in PBS. Cell membranes were permeabilised for $5 \mathrm{~min}$ in a $0.2 \%$ triton $\times$ solution. After two rinses in PBS, the cells were stained with a mixture of $0.8 \mathrm{U} / \mathrm{mL}$ TRITC-conjugated phalloidin and $5 \mu \mathrm{g} / \mathrm{mL}$ DAPI solution for $45 \mathrm{~min}$. The artificial ligament were rinsed another three times in PBS and imaged with a Leica TCS SP5 CLSM microscope.

\subsubsection{Micro-Computed Tomography $(\mu C T)$ scanning and analysis}

All ligaments $(n=3)$ were fixed in $4 \%$ paraformaldehyde solution overnight at room temperature and washed in PBS. The scans were performed in a $\mu \mathrm{CT}$ scanner ( $\mu \mathrm{CT} 40$, SCANCO Medical AG, Brüttisellen, Switzerland) at $45 \mathrm{kVp}, 177 \mu \mathrm{A}, 8 \mathrm{~W}$ at a resolution of $12 \mu \mathrm{m}$ and three-dimensional (3D) images of the structures were reconstructed from the scans by the $\mu \mathrm{CT}$ system software package. For quantitative evaluations and 3D reconstructions, a numeric threshold of 220 was utilised in order to select uniquely the signal from mineralised particles (implying the polymeric fibres of the ligament were not detected at this threshold). The volume of mineralisation and the average density of mineralisation against hydroxyapatite (HA) were calculated by the $\mu \mathrm{CT}$ software package. No negative controls (non-seeded grafted and non-grafted ligaments) were considered for this analysis as the concentration in calcium and phosphate ions is strongly affected by the cell activity and therefore prevents spontaneous mineralisation of the biomaterial surface.

\subsubsection{Statistical analysis}

A statistical analysis was performed on the data collected in the in vitro study using one-way ANOVA followed by a Tukey HSD post-hoc test in case of equal variance; otherwise a Games-Howell post-hoc test was utilised. $p<0.05$ was considered as statistically significant.

\subsection{In vivo study}

\subsubsection{Animals}

Fifty one, two-year-old, female Pré-Alpes sheep (each weighing approximately $60 \mathrm{~kg}$ on average) were obtained from a licensed vendor and reared in keeping with the guidelines published by the European Committee for Care and Use of Laboratory Animals (European Committee for Care and Use of Laboratory Animals Directive 24.11.1986. 86/609/CEE).

\subsubsection{Surgical procedure}

Anaesthesia was induced by intravenous administration of thiopental (12 mg/ $\mathrm{kg}$ ), and maintained with oxygen and isoflurane. All sheep underwent a lateral arthrotomy, an excision of the upper third of the left Anterior Cruciate Ligament (ACL) and subsequent intra-articular joint stabilization with either a grafted or ungrafted LARS ${ }^{\mathrm{TM}}$ artificial ligament (tensile strength $=2500 \mathrm{~N}$ ). Grafted ligament (GL, $n=28$ ) and non-grafted ligament (NGL, $n=23$ ) were randomly assigned Ligaments were passed through $4.5 \mathrm{~mm}$ bone tunnels drilled inside-out in the femoral and tibial metaphysis at the locations of the native ligament insertions. They were inserted so that the knitted portions of the artificial ligaments (referred herein as the bone compartment) remained in the bone tunnels and that the smooth fibres were located intra-articularly. They were subsequently cycled and secured with two $6 \mathrm{~mm}, 25-30-\mathrm{mm}$ long blunt threaded interference titanium screws. Isometry and absence of cranial drawer were controlled before closure.

\subsubsection{Postoperative care and examinations}

Standard lateral and dorsoventral radiographs were taken once surgeries were completed and a light protective dressing was applied and changed, as needed, until 
suture removal 12 days after surgery. Postoperative analgesia was provided to all sheep through intravenous injections of meloxicam ${ }^{\circledR}(0.5 \mathrm{mg} / \mathrm{kg}) 30 \mathrm{~min}$ before, at the end of, as well as $72 \mathrm{~h}$ after surgery.

Animals were left free to ambulate without restriction for the whole length of the experiment. Stifles were explanted after animal sacrifice, 3 months or 12 months postoperatively and processed for either (i) histology $(n=24)$ to assess tissue ingrowth, cellularity and presence of wear debris in the intra-osseous portions of the prosthesis; or (ii) mechanical tests including loading to failure in tension $(n=27)$ to assess the anchorage of the artificial ligament.

\subsubsection{Histology and histomorphometry}

A histological procedure for non-demineralised bone was performed in all excised tissue specimens. Each proximal part of the tibial bone (including the tibial bone tunnel) was fixed in $10 \%$ phosphate-buffer formalin, rinsed in water dehydrated in ethanol, cleared in xylene and embedded in methyl-methacrylate. Radiographs were taken to ensure appropriate defect orientation for subsequent histological sectioning. Embedded specimens ( $n=6$ at 3 months post-implantation and $n=5$ at 12 months post-implantation for non-grafted ligaments (NGL) and $n=7$ at 3 months and $n=6$ at 12 months for grafted ligament (GL)) were sectioned in a transverse manner using a circular water-cooled diamond saw (Leitz 1600, Leica ${ }^{\circledR}$ Inst., Nussloch, Germany). Sections located nearest the tibial plateau were selected for analysis. Each section was grounded-down to a thickness of $100 \mu \mathrm{m}$, using the exact Grinding system (Exact Apatebau GmbH Norderstedt Germany) and then polished down to $60 \mu \mathrm{m}$. All sections were stained with Stevenels' Blue and then with Van Gieson picro-fuchsin, using standard procedures. Tissue ingrowths within the fibres of the artificial ligament as well as the bone-ligament interface were examined for each animal. A blind analysis was performed to calculate the percentage of successful direct ligament-to-bone contact as well as the percentage of bone presence in the centre of the ligament (defined as located at least $1.5 \mathrm{~mm}$ from the periphery of the artificial ligament and determined as the number of samples displaying direct contact or bone presence divided by the total sample number). For both parameters, at least 2 direct ligament-to-bone contacts or 2 bone islets in the ligament centre were considered as successful. Histomorphometry was also performed in a blind analysis while measuring the total bone area in the ligament, the total length of direct ligament to bone contact, the total area occupied by the fibrous tissue around the artificial ligament and its average thickness. Osteomeasure software (OsteoMetrics Inc, USA) was utilised for performing this analysis and the region of interests were manually drawn on images taken at $8 \times$ magnification. Statistical analysis was performed according to the method described in Section 2.2 .7

\subsubsection{Mechanical tests: pull-out destructive tests}

The joints including the synovial capsule, the femur, the tibia, the patella and a portion of the quadricipital tendon were kept frozen at $-20^{\circ} \mathrm{C}$, and were thawed at room temperature $24 \mathrm{~h}$ before mechanical tests. Before testing, femur and tibia were cut $10 \mathrm{~cm}$ proximal and distal, respectively, to the stifle joint. All other parts of the joint were removed except for the ACL. The free ends of tibia and femur were embedded in steel cylinders using a low temperature melt alloy (MCP70). The sample number was 5 pairs of NGL and 7 pairs of GL (implanted and controlateral unoperated stifles) at 3 months post-implantation and 7 pairs of NGL and 8 pairs of GL at 12 months post-implantation. Stifles were subsequently mounted on the testing machine (Instron Ltd., Buckinghamshire, England) instrumented with a $5 \mathrm{kN}$ load cell (accuracy $0.5 \%$ ) in such a way that tension loading was applied in line with femoral and tibial tunnels (this position was chosen to simulate a worst-case scenario). Tests were carried out at room temperature and the stifles were kept moisturised using a saline solution; Briefly, stifles were conditioned using 10 loading-unloading cycles between 5 and $50 \mathrm{~N}$ (using a $5 \mathrm{~mm} / \mathrm{min}$ loading-unloading speed) followed by $120 \mathrm{~s}$ relaxation at $100 \mathrm{~N}$ to assess the viscoelasticity component of the biomechanical behaviour. Finally, a tension load until total failure was applied to the specimen $(5 \mathrm{~mm} / \mathrm{min})$. The experimental load-elongation curve was recorded and tests were video-recorded. Failure mode and ultimate failure load were documented. Control, un-operated, controlateral joints were tested similarly. Statistical analyses were performed using a non-parametric Mann-Whitney test to evaluate the effect of implantation time on biomechanical properties and the difference between grafted and non-grafted synthetic ligaments, $p<0.05$ was considered as statistically different.

\section{Results}

\subsection{Grafting characterisation}

XPS was used to determine the atomic composition of the surface for each type of sample (ozonated, non-grafted and grafted). Table 1 gives a summary of the XPS determined elemental composition results for the PET controls and the PolyNaSS grafted PET samples. The XPS determined elemental composition of the as
Table 1

XPS composition of PET samples ${ }^{\mathrm{a}}$.

\begin{tabular}{lllll}
\hline & \multicolumn{2}{l}{ XPS atomic \% } & & \\
\cline { 2 - 5 } & $\mathrm{C}$ & $\mathrm{O}$ & $\mathrm{Na}$ & $\mathrm{S}$ \\
\hline PET Theory & 71.4 & 28.6 & $\mathrm{n} / \mathrm{d}$ & $\mathrm{n} / \mathrm{d}$ \\
NaSS Theory & 61.5 & 23.1 & 7.7 & 7.7 \\
PET As Is & $73.5 \pm 0.3$ & $25.8 \pm 0.3$ & $\mathrm{n} / \mathrm{d}$ & $\mathrm{n} / \mathrm{d}$ \\
PET Ozonated $^{\mathrm{b}}$ & $75.7 \pm 0.8$ & $24.3 \pm 0.8$ & $\mathrm{n} / \mathrm{d}$ & $\mathrm{n} / \mathrm{d}$ \\
1 h NaSS & $69.4 \pm 2.5$ & $23.5 \pm 0.8$ & $3.8 \pm 1.4$ & $3.2 \pm 0.6$ \\
\hline
\end{tabular}

a Some samples showed Trace amounts $(<0.1 \%)$ of phosphorous and/or fluorine and/or silicon.

b Ozonated for $30 \mathrm{~min}$.

received PET was similar to that expected from theory, but with a slight excess of more carbon. Sodium and sulphur were not detected on the as received control, and a negligible amount $(\leq 0.1 \%)$ of sulphur was found on one of the ozonated samples. It should be noted that the ozonation process produces a highly reactive surface that may adsorb contaminants when removed from the chamber. Some of the PolyNaSS grafted samples showed trace $(<0.1 \%)$ amounts of phosphorous, fluorine, and/or sodium contamination (not shown in Table 1). The reaction of NaSS with the ozonated samples resulted in an increase in sodium and sulphur concentrations on the surface and a corresponding decrease in the overall percentage of carbon and oxygen, as expected for grafting of PolyNaSS from the PET surface (see Table 1 for the different theoretical elemental compositions of NaSS and PET). $3-4 \%$ of sulphur was detected on the surface of the PolyNaSS grafted bone compartment samples [20]. The XPS compositions of the PolyNaSS grafted ligament are consistent with the presence of a few nanometer thick layer of PolyNaSS grafted from the PET surface after a 60 min reaction.

XPS high resolution scans of the $\mathrm{C} 1 \mathrm{~s}$ region can give added detail about the changes on the PET surface due to each modification step. Representative high-resolution $\mathrm{C} 1 \mathrm{~s}$ data from ozonated and NaSS grafted PET tissue samples are shown in Fig. 2 a). The ozonated PET tissue sample HRC shows a strong hydrocarbon peak $(C-C)$, a shoulder which is attributed to the ether $(\mathrm{C}-\mathrm{O})$ type carbon, and a higher binding energy peak from the ester peak $(\mathrm{O}=\mathrm{C}-\mathrm{O})$ of PET. This spectrum was typical of a standard PET sample, which we already reported in previous publications $[19,20]$. Once the NaSS was grafted from the PET surface there was a decrease in the $\mathrm{C}-\mathrm{O}$ and $\mathrm{O}=\mathrm{C}-\mathrm{O}$ peak intensities relative to the $\mathrm{C}-\mathrm{C}$ (hydrocarbon) peak intensity. This is the expected result for NaSS grafting (with the six carbon styrene group) to a PET surface. A summary of the HRC data peak fit results for the PET tissue samples is given in Table 2 . The as received and ozonated samples had peak areas for the $\mathrm{C}-\mathrm{C}(285 \mathrm{eV}), \mathrm{C}-\mathrm{O}(286.6 \mathrm{eV})$ and $\mathrm{O}=\mathrm{C}-\mathrm{O}(289.3 \mathrm{eV})$ carbon species that were similar to those expected for a standard PET sample. A shakeup peak at $\sim 291 \mathrm{eV}$ (due to the aromatic ring of PET) was also observed for non-grafted samples. Once the NaSS was grafted from the PET surface, the hydrocarbon peak increased relative to the ether and ester peaks. The ether and ester peaks are unique to the PET substrate while hydrocarbon is likely due to the addition of the NaSS, so the increasing hydrocarbon peak is consistent with the addition of NaSS to the surface. The covalent nature of the polyNaSS grafting on the artificial ligament resulted in a very high stability.

The macroscopic distribution of the grafting materials was investigated by toluidine blue staining and revealed that the pol$y N a S S$ had effectively infiltrated the centre of the artificial ligament as shown in Fig. 2 b and c (blue colour) and that each individual polymeric fibre was effectively grafted. This is of significance as a homogeneous grafting distribution is desirable for promoting bone anchorage throughout the artificial ligament. 
a

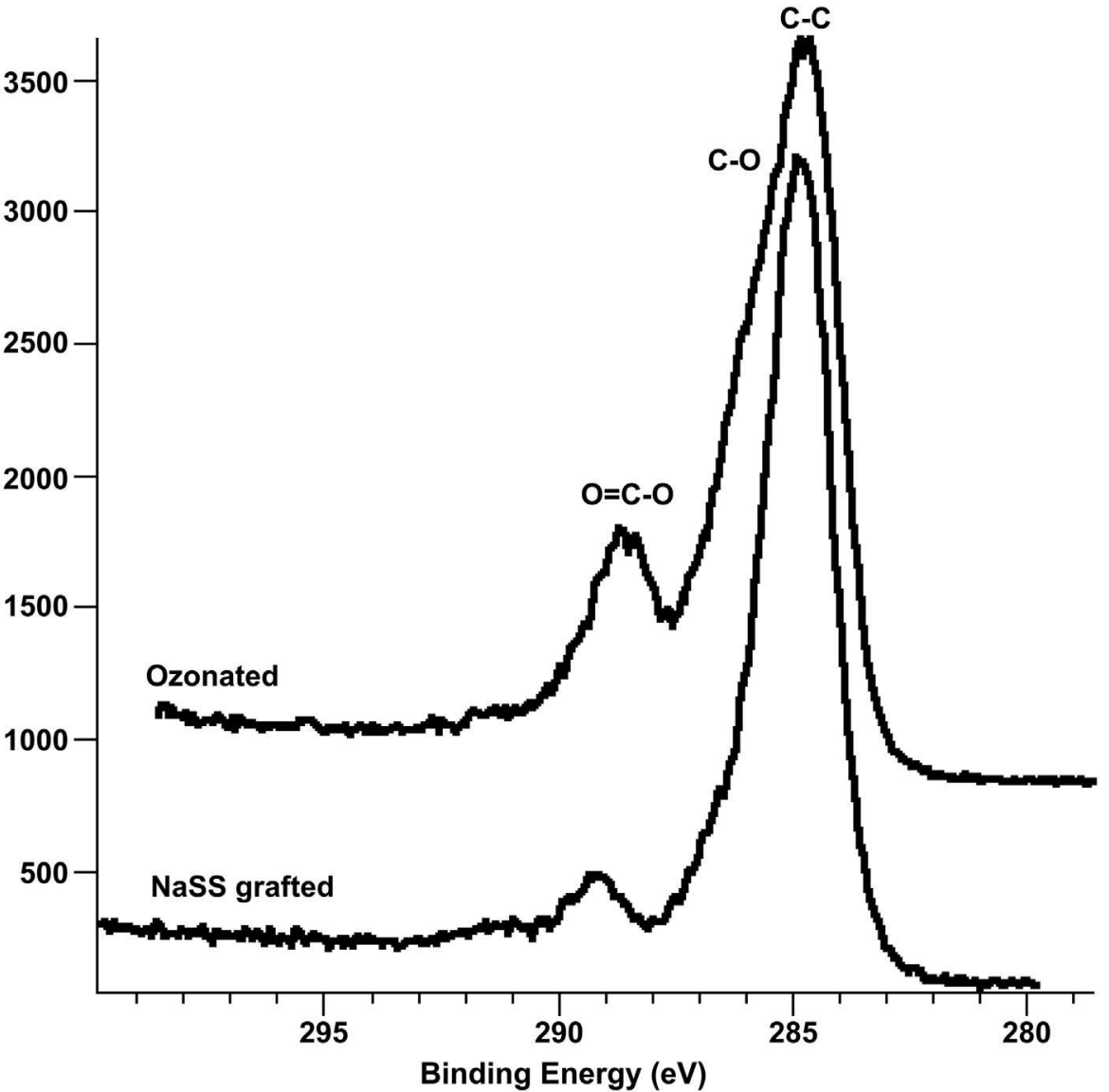

b

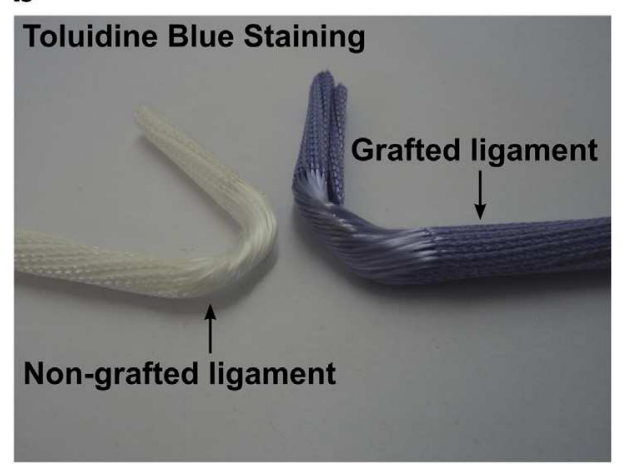

C

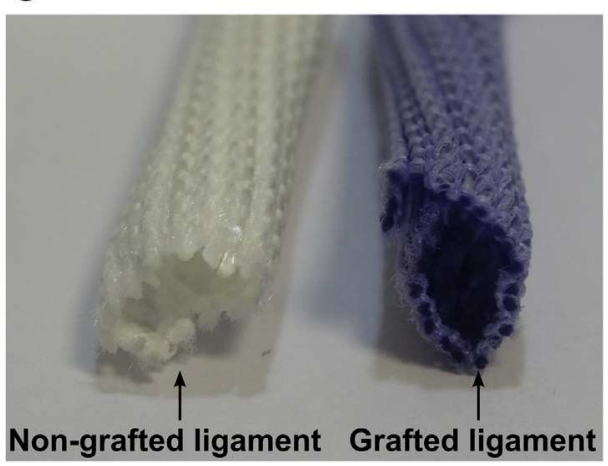

Fig. 2. Characterisation of the grafting: a) XPS High resolution C1s of PET tissue samples with various surface modifications. Data has been calibrated to C-C peak at 285 eV. Macroscopic distribution of the grafting material as seen by toluidine blue staining: b) global view and c) cross-section of the ligament bone compartment. (For interpretation of the references to colour in this figure legend, the reader is referred to the web version of this article.)

Table 2

XPS high resolution C1s peak fit results for PET fibre samples modified with NaSS.

\begin{tabular}{lllll}
\hline & \multicolumn{3}{l}{$\mathrm{C} 1 \mathrm{~s}$ species (percent) } \\
\cline { 2 - 5 } $\mathrm{C}-\mathrm{C} / \mathrm{C}-\mathrm{H}$ & $\mathrm{C}-\mathrm{O} / \mathrm{C}-\mathrm{SO}_{3}$ & $\mathrm{O}=\mathrm{C}-\mathrm{O}$ & $\begin{array}{l}\text { Shakeup } \\
\text { satellite }\end{array}$ \\
\hline B.E. (eV) & $(285.0)$ & $(286.6)$ & $(289.3)$ & $(291)$ \\
PET Theory & 60 & 20 & 20 & \\
NaSS Theory & 87.5 & 12.5 & & 3 \\
PET As Is & 56.0 & 24.0 & 17 & 3 \\
PET ozonated & 55.0 & 25.0 & 17 & 2 \\
1 h NaSS & 73 & 16 & 4 & \\
\hline
\end{tabular}

\subsection{In vitro study}

\subsubsection{DNA-content and ALP expression}

The DNA content analysis showed that more cells had significantly adhered onto the polystyrene sodium sulfonate grafted structures as shown in Fig. 3 a). However at week 2 post-seeding this trend was inverted and there was more cells present on the non-grafted specimens. From week 2 and week 4, DNA content and therefore the cell number, significantly decreased for both types of ligament. Such observation could be explained by reduced nutrient and oxygen availability to the cells in the more central portion of the artificial ligament, as a result of poor diffusion. Interestingly, this was more pronounced for the grafted ligaments, possibly due 
to initial higher cell attachment in this group caused by the grafting material. Therefore a thicker cell layer was formed, which further impeded the diffusion of nutrient and oxygen within the ligament. Cells did not proliferate into the non-grafted samples from week 4 to week 6 whereas a significant increase in the cell number was observed for the grafted structures. Six weeks post-seeding, the grafted samples displayed a higher level of DNA content compared to non-grafted specimen as depicted in Fig. $3 \mathrm{~b}$ ) although this was not a significant difference. As previously mentioned in Section 2.2.3, the ALP activity was normalised by the DNA of the same sample enabling the precise measurement the osteoblastic performance on both artificial ligament. We observed a significant increase in ALP activity for the grafted specimens at week 2 and 4 compared to non-grafted samples, however at week 6 whilst there was an observed ALP increase, it did not reach statistical significance (Fig. 3 c). The non-grafted samples did not display significant
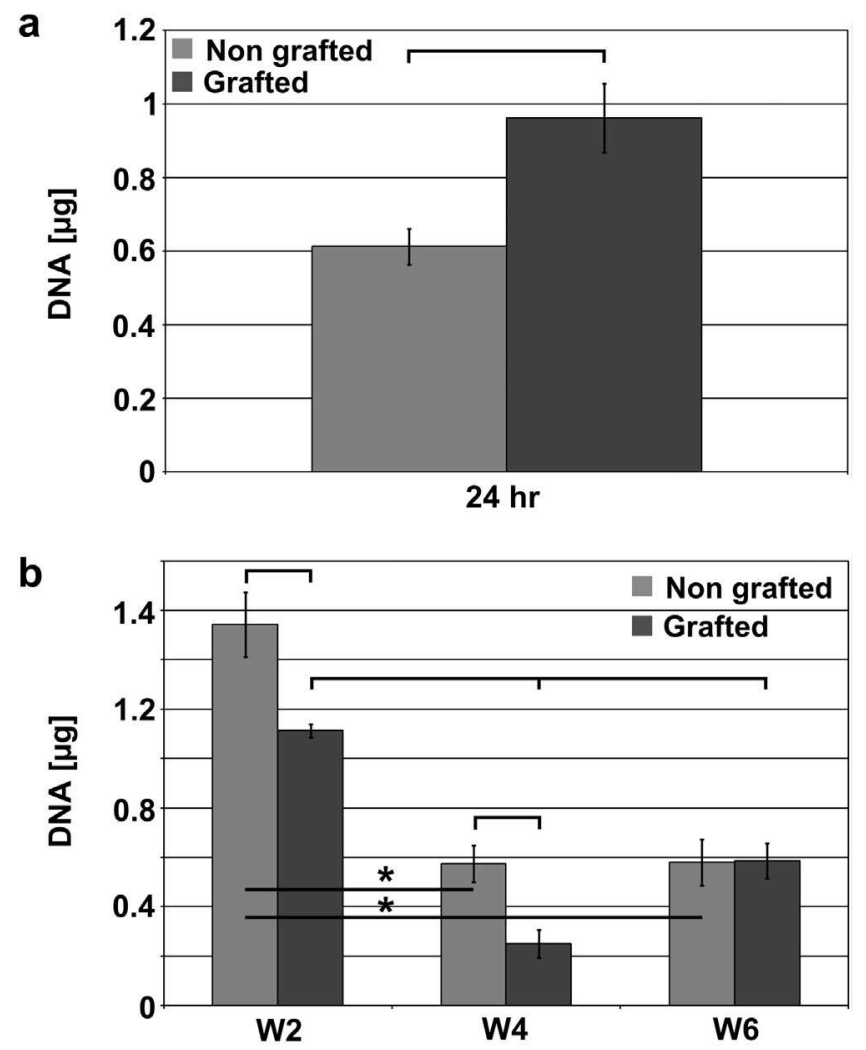

C

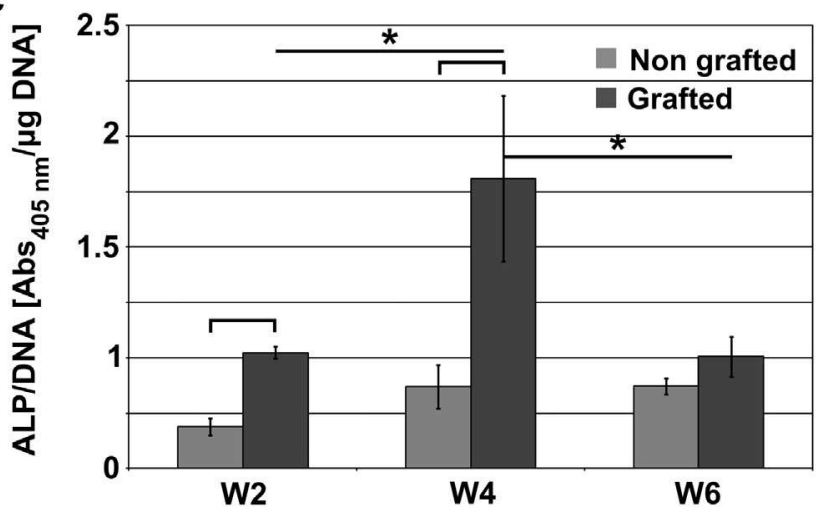

Fig. 3. DNA contents and APL expressions during the in vitro culture. a) DNA contents at 24 h post-seeding, b) DNA content at week 2,4 and 6, c) normalised ALP expressions. Stars and bars show statistical difference $\mathrm{p}<0.05$. changes throughout the in vitro culture although a slight but nonsignificant increase occurred at week 4 . Similarly, the ALP activity peaked at week 4 for the grafted structures. Hence, in this study, it was observed that the polystyrene sulfonate grafting had a beneficial effect onto the in vitro ALP secretion from human osteoblasts in osteogenic conditions.

\subsubsection{Cell imaging}

Confocal laser scanning microscopy showed that a dense cellular network was formed on the surface of both GL and NGL throughout the entire in vitro culture as depicted in Fig. 4. There was no significant difference in cell morphology between NGL and GL. We observed that the osteoblasts seemed to proliferate on the surface of the samples (regardless if grafted or not) as more nuclei were observed at week 4 and 6 compared to week 2 . Also, they were orientated along the polymer filaments of the braided structures and Scanning electron microscopy confirmed this observation and the formation of a dense cell sheet covering both types of structures could be observed at week 4 and 6 . The formation of such dense cell sheet could limit the diffusion and availability of nutrients and oxygen to those underlying cells. These observations correlate to the sharp decrease in cell number observed from week 2 to week 4 (Fig. 3 b).

\subsubsection{Evaluation of the mineralisation}

The mineralisation was qualitatively assessed by alizarin Red $S$ staining and this experiment showed that the deposition of mineralised extracellular matrix was preferentially located on the surface of both GL and NGL as illustrated in Fig. 5. Indeed, when the scaffolds were longitudinally sectioned, the central portions of the structures remained unstained. It was also observed that the samples for both groups were more stained at week 4 and 6 when compared with week 2 . However, no noticeable differences were found between non-grafted and grafted samples for all time points and this was believed to originate from the inaccuracy of the experimental method.

Micro-Computed Tomography $(\mu \mathrm{CT})$ was performed in order to quantitatively measure the deposition of mineralised matrix in these two types of structure. As shown in Fig. 6 a, the signal detected by the $\mu \mathrm{CT}$ remained around the noise level at week 2 and week 4. However, at week 6 mineralised particles on the grafted structures could be measured whereas the non-grafted group did not show any significant signal. This indicated that the sodium polystyrene sulfonate grafting induced superior mineralisation in vitro. Fig. $6 \mathrm{~b}$ displays representative 3D reconstructions of the $\mu$ CT scans for both NGL and GL. The deposition of mineralised particles in GL was mostly located at the periphery of the specimens and, here again; the central parts of the structures remained free of mineralisation.

EDXS was performed on mineralised particles for both groups as illustrated in Fig. 7. It was found that the calcium/phosphorus ratio $(\mathrm{Ca} / \mathrm{P})$ was measured at $1.77 \pm 0.12$ and $1.68 \pm 0.11$ for NGL and GL respectively. No significant differences were observed between these two groups indicating that the composition and therefore the phase of the newly formed mineralised matrix was similar for the two groups and consistent with hydroxyapatite $(\mathrm{Ca} / P=1.66)$.

\subsection{In vivo study}

\subsubsection{Clinical outcome}

All 51 animals in the study recovered successfully from the surgical procedures and remained in good health throughout the duration of this study. Monthly postoperative examinations showed constant normal weight bearing in all but four animals (in which constant subtle weight bearing was observed, 12 months postoperatively), at all strides. 

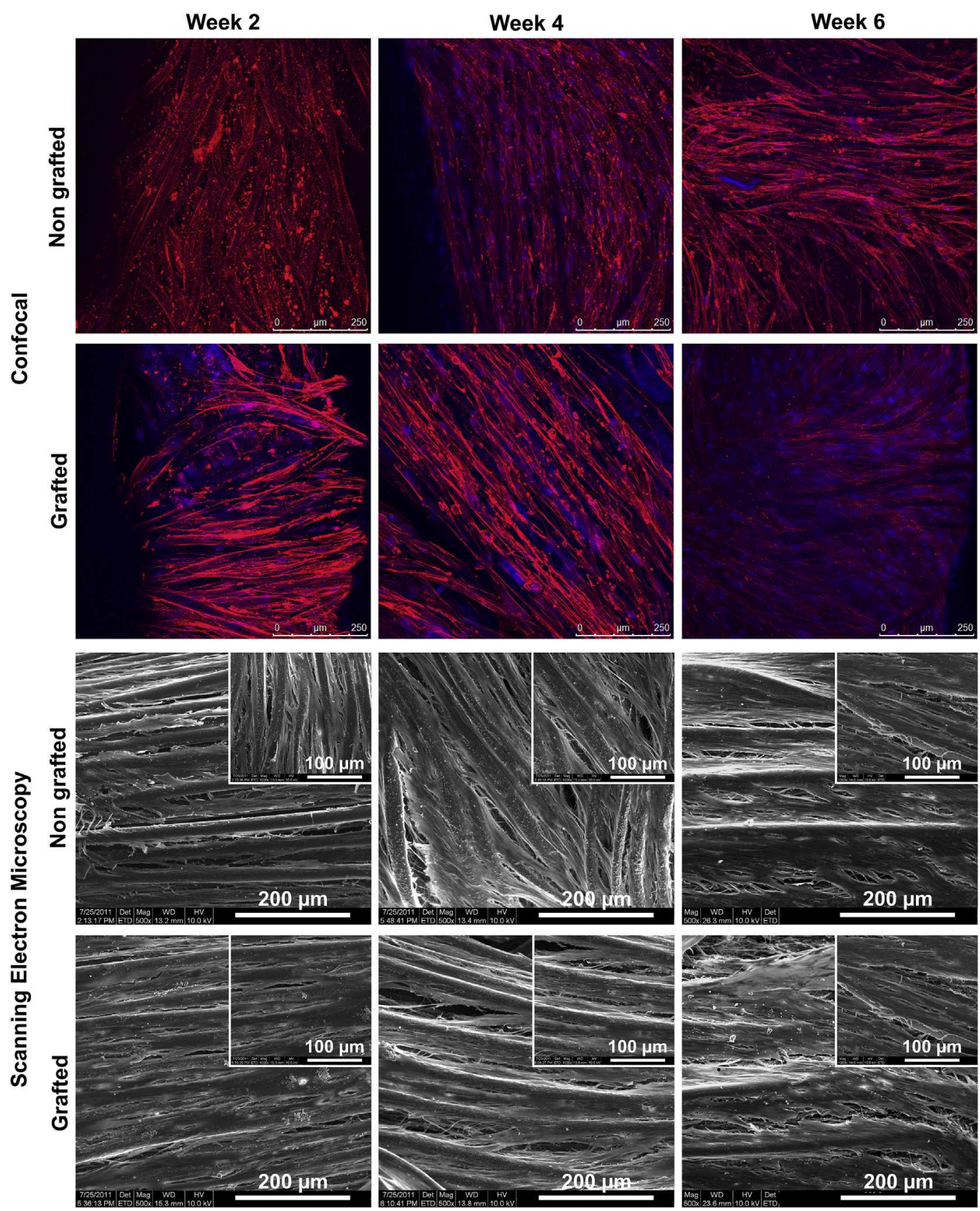

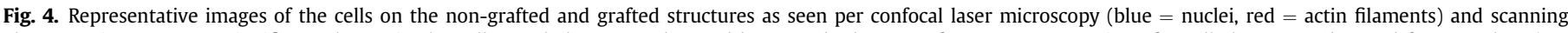

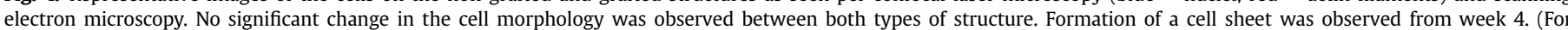
interpretation of the references to colour in this figure legend, the reader is referred to the web version of this article.)

\subsubsection{Necropsy findings}

Wear, resulting in partial rupture of the intra-articular portion of the artificial ligaments was observed in 20/51 explanted specimens. 11 specimens (4 specimens implanted with a GL and 7 specimens implanted with an NGL) and 9 specimens (4 specimens implanted with a GL and 5 specimens implanted with an NGL) were explanted 3 and 12 months postoperatively, respectively. Wear was always located at the level of the medial aspect of the lateral femoral condyle or just above the tibial plateau, in all cases in the vicinity of the bone tunnel opening.

The cause of artificial ligament wear could not be determined with certainty in our study. Many factors such as inappropriate bone tunnel positioning, cyclic bending of the ligament around sharp bony edges, friction between fibres and loss of fixation of the artificial ligament that are observed in human subjects could also be responsible for the ligament wear. However, the challenging biomechanical environment (unrestricted postoperative activity, narrow intercondylar notch and increased tibial slope in the sheep knee) in which the ligament was tested may also explain the high incidence of wear observed in our ovine model.

\subsubsection{Histological observations}

Histological observations revealed that cell and tissue infiltration had already occurred three months post-implantation in both non-grafted and grafted artificial ligaments and the host tissue completely colonised the artificial ligaments. Giant cells were 

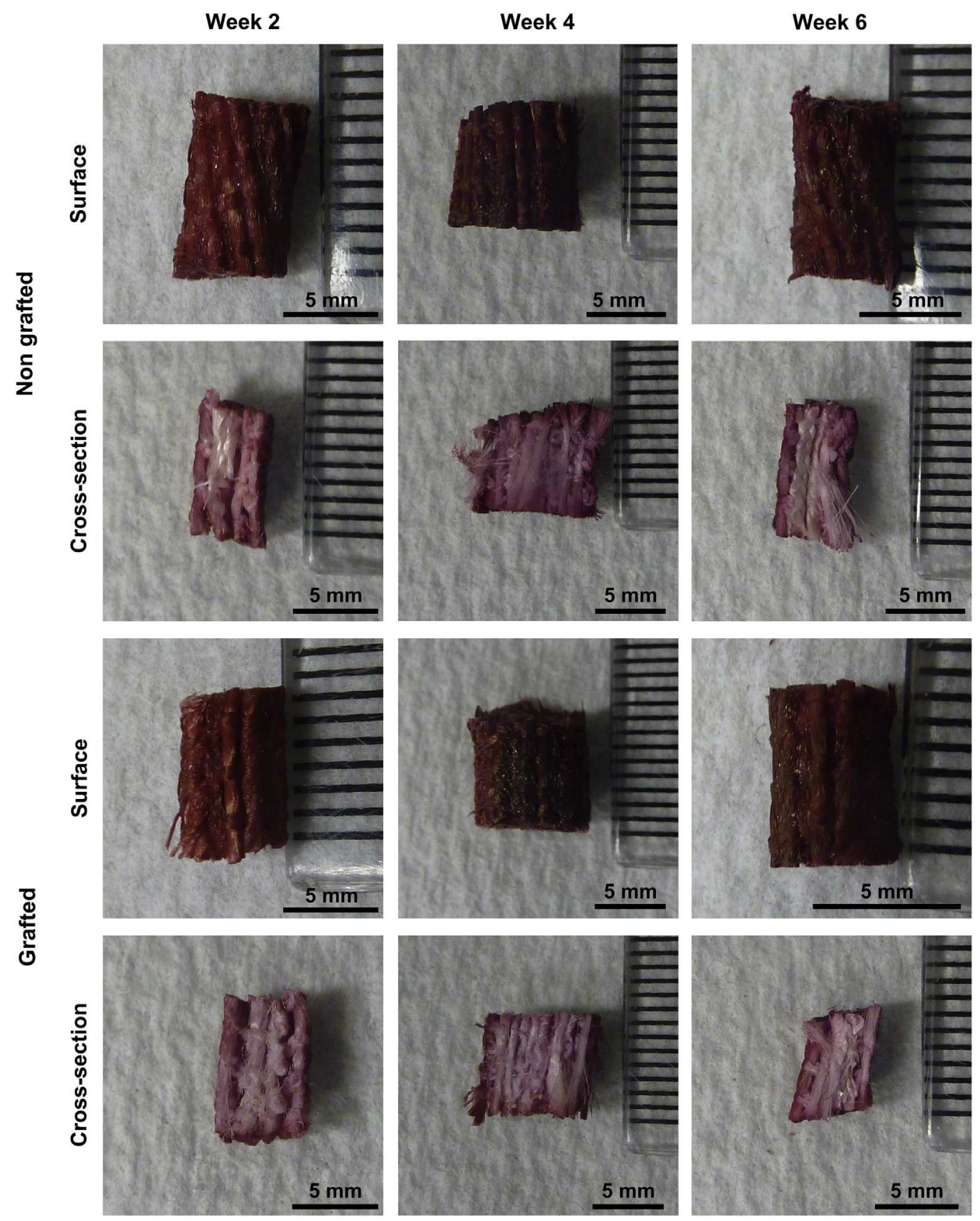

Fig. 5. Representative images of the alizarin Red $\mathrm{S}$ stained structures. The staining was more intense at week 4 and 6 post-seeding. There was no staining in the interior of the samples.

observed in the direct vicinity of the ligament but also in between the artificial fascicles and fibres exemplifying that a moderate inflammation occurred. Three months post-implantation in the vast majority of samples a connective fibrous tissue encapsulated the PET fascicles regardless of the PolyNaSS grafting as denoted by the stars in Fig. 8 a and $d$. The connective tissue at the boneligament interface was well vascularised, highly cellularised and consisted of a mixture of non-oriented as well as perpendicular fibres to the surrounding bone. The well-organised, perpendicular to bone, Sharpey-like collagen fibres tended to attach to the artificial ligament and the surrounding bone. This fibro-vascular tissue surrounded the artificial ligament and had a heterogeneous thickness as shown in Fig. 8 a, d. Histomorphometry analysis revealed that the thickness of this connective tissue was around 350 microns regardless of the ligament surface modification (Fig. 9 a). The surface covered by the fibrovascular tissue was around $9 \mathrm{~mm}^{2}$ with no statistical difference between NGL and GL (Fig. 9 b). When this connective tissue was not present at the bone-ligament interface, direct ligament-to-bone contact could be observed for both groups (Fig. 8 b, c and e, f as denoted by the white arrows). Direct contact and bone formation around the grafted PET fibres was observed in $28 \%(2 / 7)$ of the grafted specimens and in $33 \%(2 / 6)$ in the case of non-grafted ligaments (as shown in Table 3 ). When direct ligament-to-bone contact was present, the individual PET fibres were either in partial contact or intimately embedded in the newly formed bone matrix as shown in Fig. 8 b, c (arrows) and e-f for 

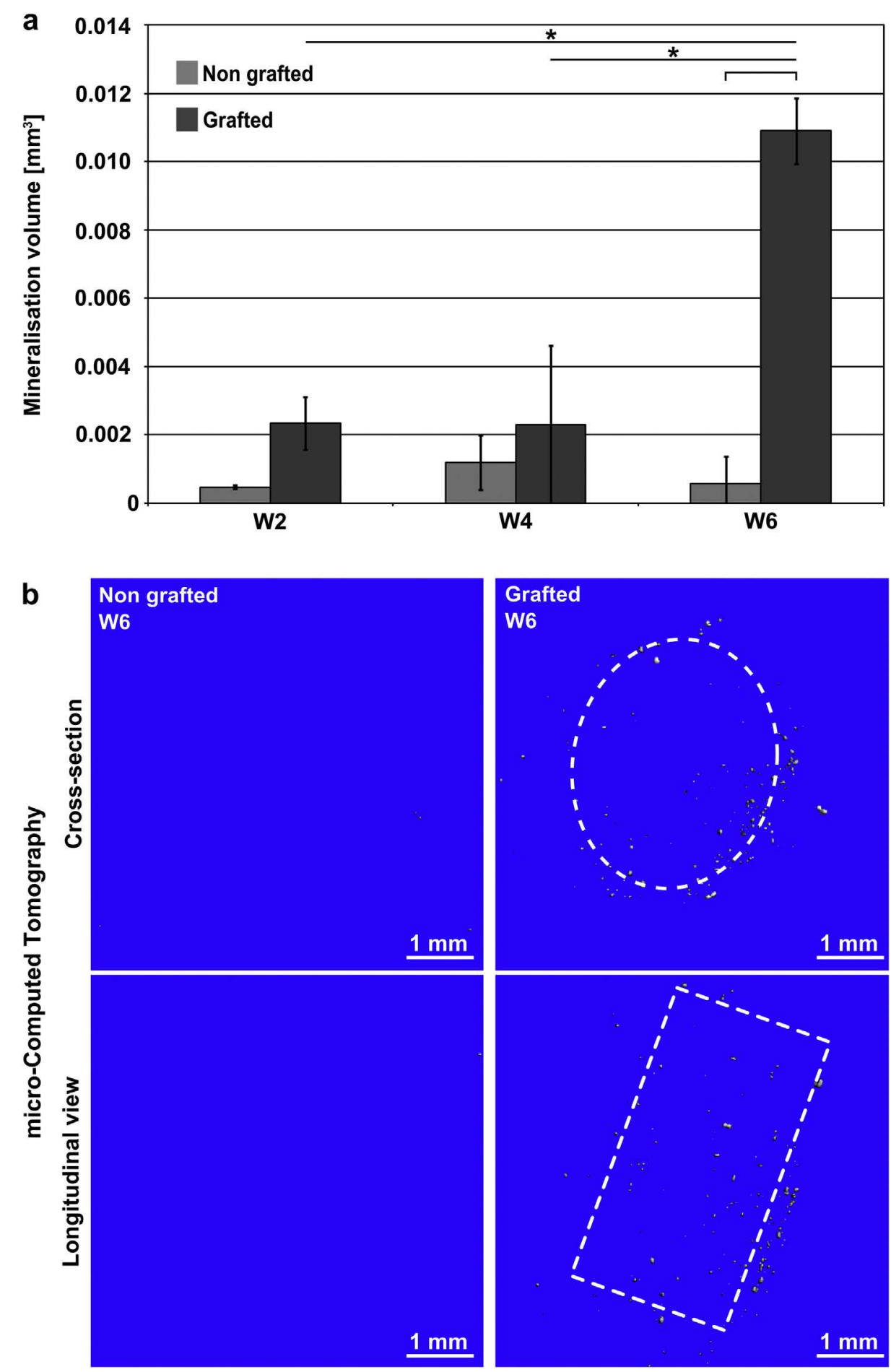

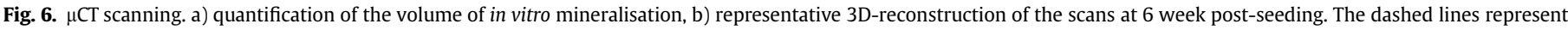
the approximate location of the structures. Bars and stars represent statistical significance $(p<0.05)$.

respectively non-grafted and grafted ligament. Presence of bone in the core of the artificial ligaments was detected in $33 \%(2 / 6)$ and $28 \%(2 / 7)$ of the specimens for non-grafted and grafted groups respectively. Although the surface covered by bone in the ligament was higher in the GL specimens, it did not reach statistical significance (Fig. 9 c). Similarly, the total length of ligament to bone contact 3 months post-operatively was around $3-3.5 \mathrm{~mm}$ and was not statistically different.
At twelve months post implantation, the fibro-vascular tissue layer, when present at the bone-ligament interface, appeared thicker and denser compared to that observed three months postimplantation in NGL (Fig. $8 \mathrm{~g}-\mathrm{l}$ ). This was corroborated by the quantitative evaluation of the fibrous tissue thickness, which increased to 600 microns for the NGL group although it did not reach statistical significance due to the great heterogeneity seen within each sample. It is worth noting that in the case of the grafted 


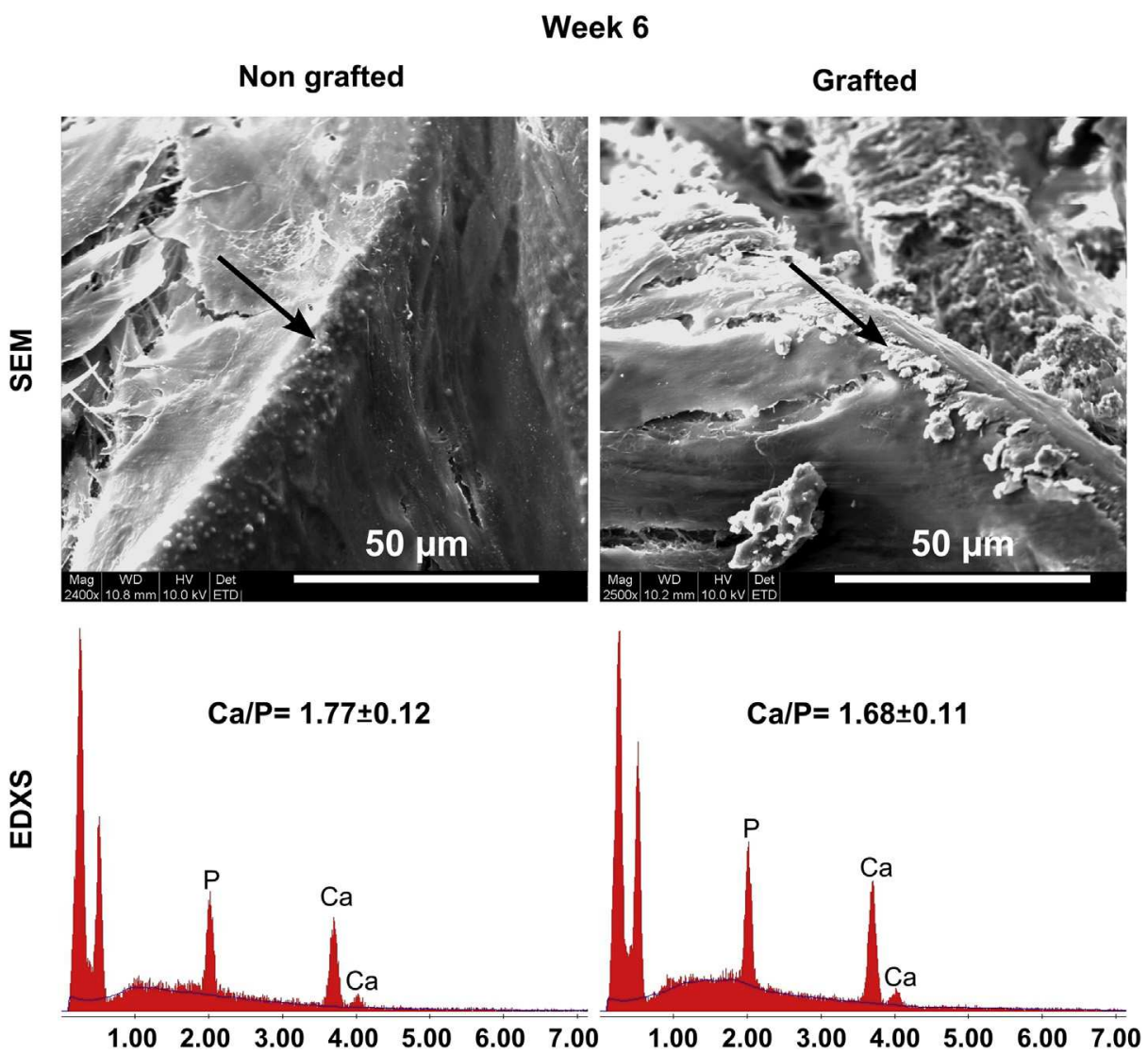

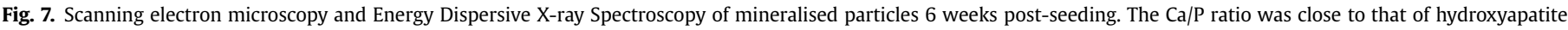
(1.66).

specimens the thickness of the connective tissue remained constant between 3 and 12 months post-implantation (Fig. 9 a). However the surface covered by the fibrous tissue was found significantly lower in the GL (Fig. 9 b) compared to NGL, suggesting that the PolyNaSS grafting directly influenced the fibrous tissue encapsulation. Although this parameter, in the case of the grafted group, decreased between 3 and 12 months post-implantation it did not reach statistical significance. Some giant cells were still observed in all specimens explanted at 12 months post implantation, albeit in smaller numbers, indicating that even though the inflammatory reaction was reduced it was still present. Direct ligament-to-bone contact was observed around PET fibres in both groups (Fig. $8 \mathrm{~g}-1$ ) but more frequently in the case of the grafted ligament. Indeed, bone-embedded PET fibres were seen only in $20 \%$ $(1 / 5)$ of the specimens in the non-grafted ligaments whereas direct ligament-to-bone contact was observed in most of the polyNaSS grafted ligaments (83\%) (5/6). Although the area covered by the bone in the centre of the ligament was not significantly different between NGL and GL (Fig. 9 c), bone formation occurred more frequently in the case of the grafted specimens $(66 \% ; 4 / 6)$ as opposed to the non-grafted specimens $(20 \% ; 1 / 5)$. Interestingly this parameter increased for the grafted samples whereas the opposite trend was observed for the non-grafted ligament suggesting that bone ingrowths around the non-grafted ligaments is impeded over time. In addition the total length of ligament to bone direct contact was significantly higher in GL than in NGL and this parameter significantly increased from 3 to 12 months post-implantation for the grafted specimens whereas it remained constant for the nongrafted ligaments (Fig. 9 d). These results demonstrated that PolyNaSS grafting on the PET surface promoted in vivo osteoblast function pertinent to new bone formation around and into the grafted artificial ligaments.

\subsubsection{Tensile tests}

The results presented in Fig. 10 correspond to 7 and 8 animals implanted with the grafted ligament ( 3 and 12 months after implantation respectively) and to 5 and 7 animals implanted with the non-grafted ligament ( 3 and 12 months after implantation respectively). For each animal, both operated and controlateral unoperated limbs were tested. Failure load of reconstructed stifles with grafted ligaments $(188 \pm 52 \mathrm{~N}$ and $322 \pm 170 \mathrm{~N}, 3$ and 12 months after implantation) were similar to the ones obtained in stifles with nongrafted ligaments ( $144 \pm 69 \mathrm{~N}$ and $260 \pm 126 \mathrm{~N}) 3$ and 12 months after implantation, respectively (Fig. $10 \mathrm{a}$ ). For both grafted and nongrafted and at both time points, failure loads remained inferior to the ones of intact, contralateral joints. Indeed at 3 months postimplantation both artificial ligaments reached around 15\% of the failure load of the intact ligament. Grafted ligaments display higher normalised failure load (around 32\%) compared to non-grafted specimens (21\%) although this did not reach statistical differences (Fig. $10 \mathrm{~b}$ ).

For the three months group, failure occurred by artificial ligament pull-out from either the tibial or femoral tunnels in 4 specimens implanted with a grafted ligament and in 2 specimens implanted with a non-grafted ligament. In 3 specimens implanted with a grafted ligament and 3 specimens implanted with a nongrafted ligament, failure occurred at mid-substance. For the 12 months group, 3 specimens implanted with a grafted ligament and 2 specimens implanted with a non-grafted ligament failed by graft pull-out from either the tibial or femoral tunnels. 5 


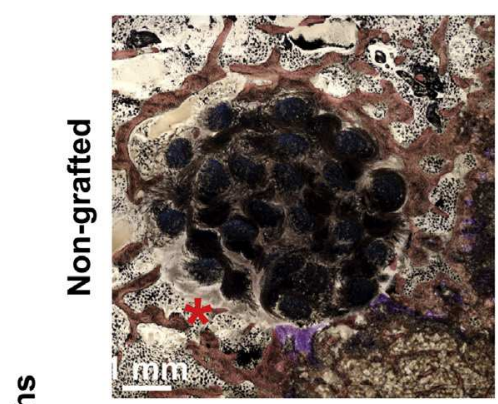

a

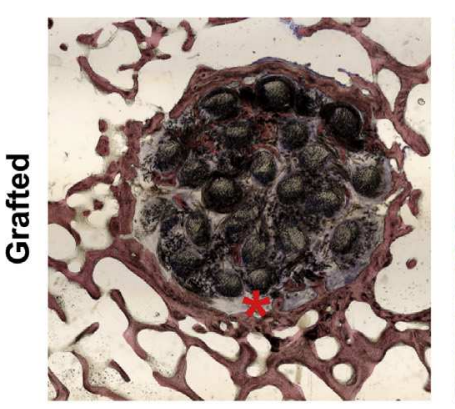

d

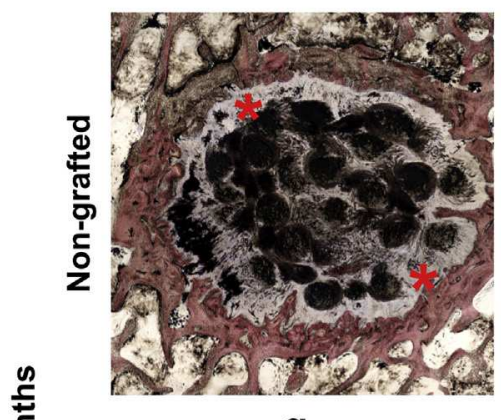

g

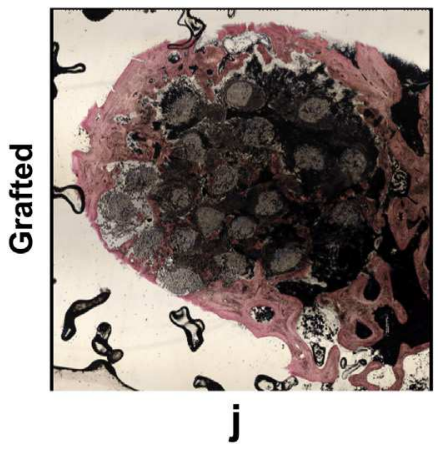

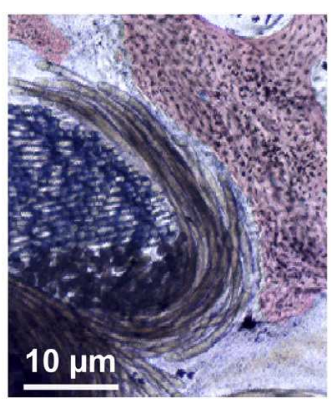

b

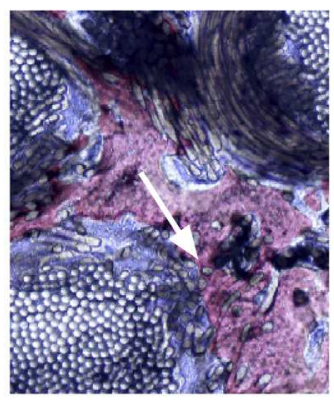

e

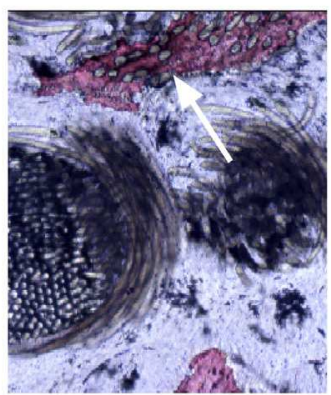

$\mathbf{h}$

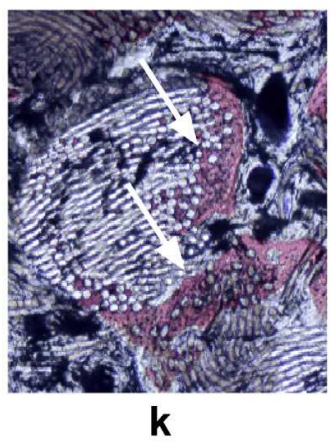

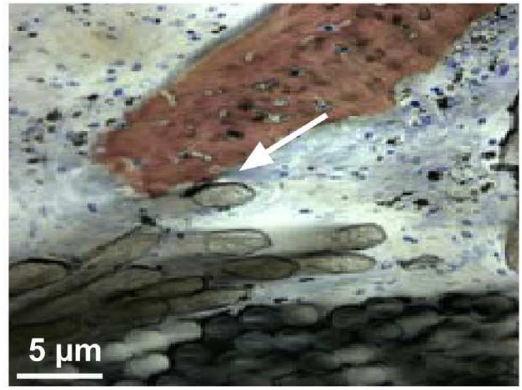

C

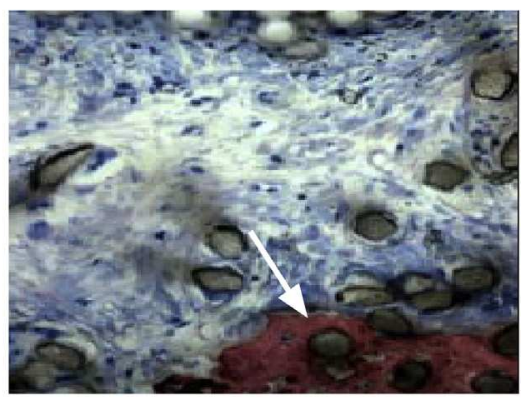

f

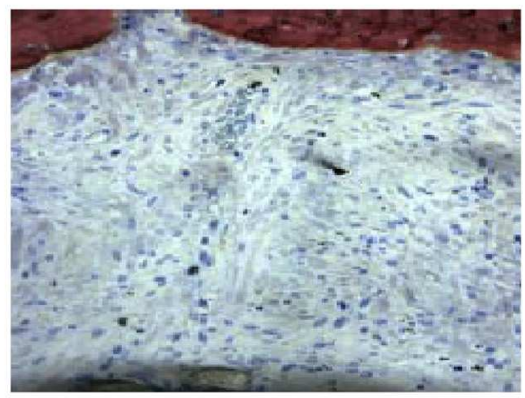

i

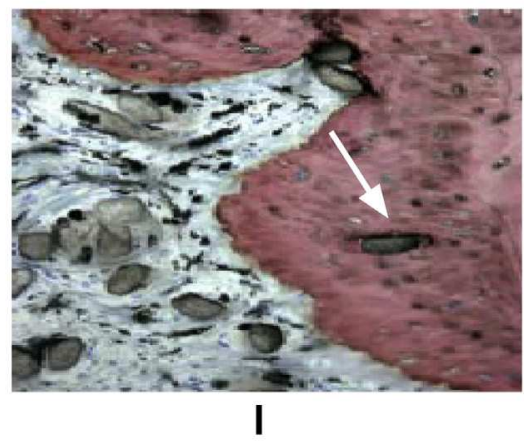

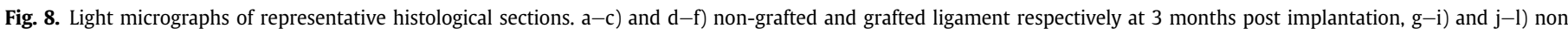

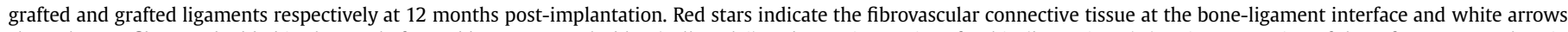

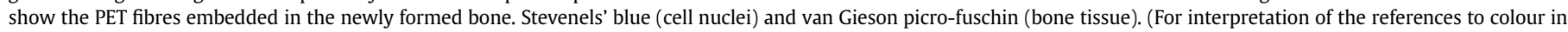
this figure legend, the reader is referred to the web version of this article.)

specimens implanted with a grafted ligament and 5 specimens implanted with a non-grafted ligament failed by ligament rupture (Table 4). Failure modes were similar between grafted and nongrafted ligaments at both time points. In both groups, ligamentto-bone fixation improved between 3 and 12 months postoperatively as documented by a decrease in the number of failure occurring by ligament slippage from bone tunnels between both time points.

\section{Discussion}

Over the last few decades, ACL reconstruction has been emulated with the development of biodegradable three-dimensional scaffolds [25-33] that are believed to circumvent the limitations associated with conventional surgical procedures. Indeed, the solution of biodegradable scaffolds is very attractive but the proposed structures, when they possess high tensile strength, they do not possess 


\section{a}
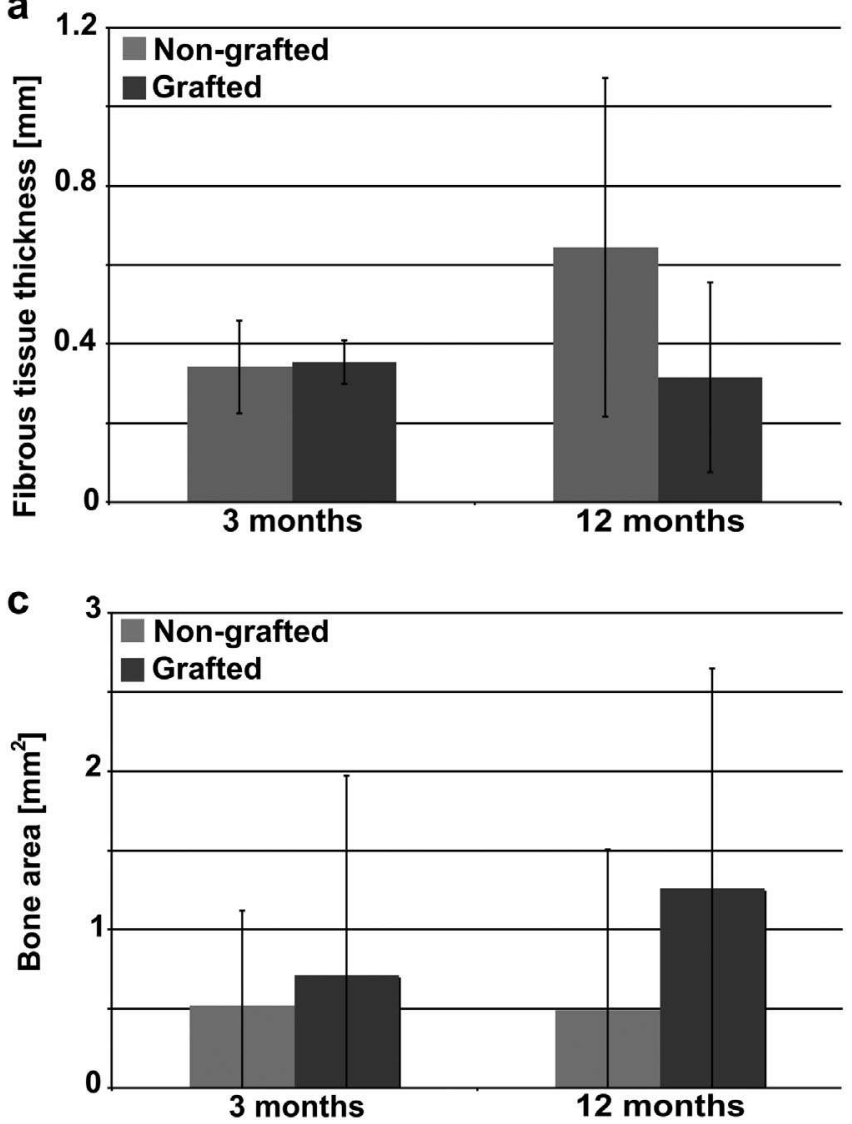

b
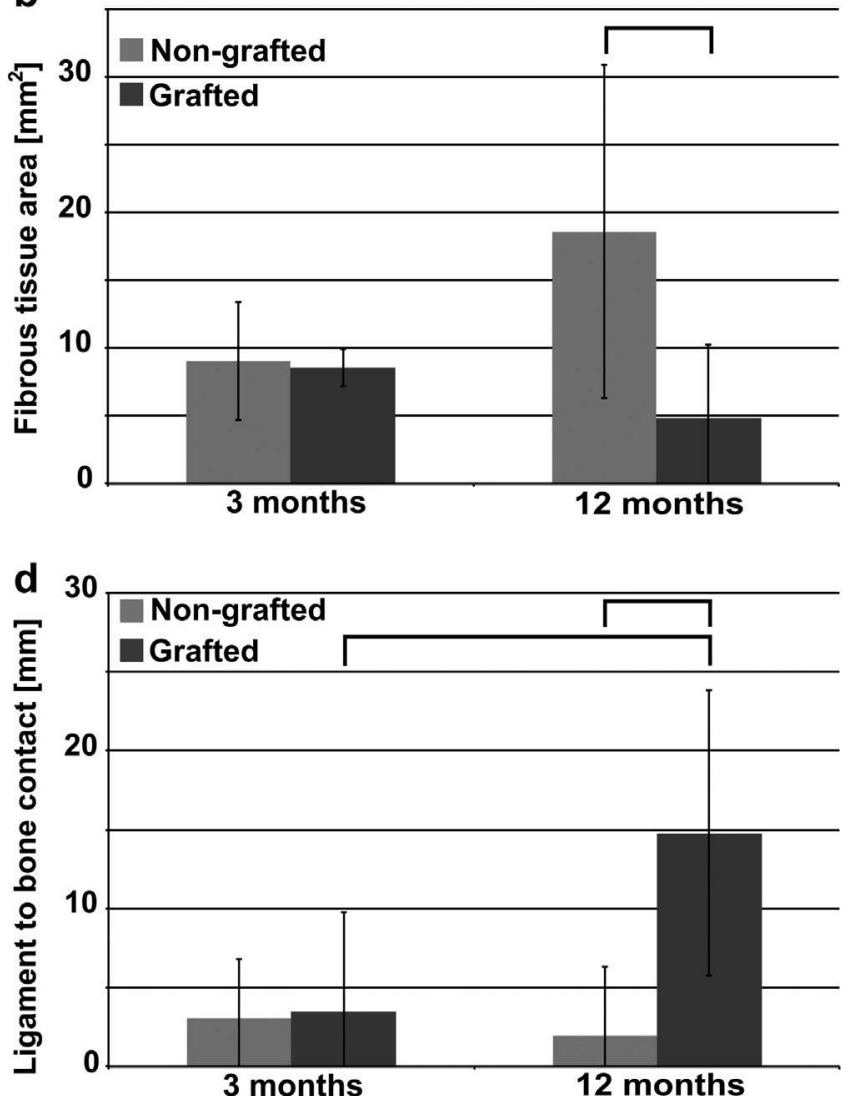

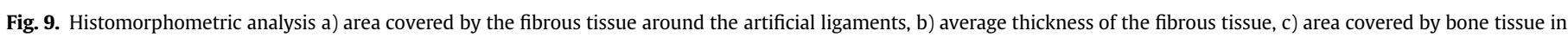
the ligament, d) total length of ligament-to-bone contact. Bars denote statistical significance $(p<0.05)$.

high porosity for permitting adequate cell infiltration and tissue colonisation. Other structures developed for more holistic tissue engineering strategies are often too fragile (ultimate strength generally do not exceed $100-200 \mathrm{~N}$ ) [30,32,34] and still need to be improved. Also biodegradable polymers used to fabricate these scaffolds generally exhibit too rapid degradation, resulting in the decrease in the scaffold's mechanical properties hence significantly limiting their utilisation in ligament reconstruction [33,34]. Although these structures are envisioned as the "future" ligament prostheses, there is still a lot more research, both in vitro and in vivo that needs to be conducted before they can be transposed from bench to bedside.

Table 3

Percentage of direct ligament-to-bone contact and percentage of bone presence in the ligament core for non-grafted and grafted groups (determined as the number of samples displaying direct contact or bone presence divided by the total sample number).

\begin{tabular}{lll}
\hline & \multicolumn{2}{l}{ Direct ligament-to-bone contact } \\
\cline { 2 - 3 } & 3 months & 12 months \\
\hline Non grafted & $33 \%$ & $20 \%$ \\
Grafted & $28 \%$ & $83 \%$ \\
\hline & Presence of bone in the ligament core \\
\cline { 2 - 3 } & 3 months & 12 months \\
\hline Non grafted & $33 \%$ & $20 \%$ \\
Grafted & $28 \%$ & $66 \%$ \\
\hline
\end{tabular}

Non resorbable synthetic ligaments such as LARS ${ }^{\mathrm{TM}}$ present advantages over other existing solutions in relation to availability, initial strength and have already demonstrated promising clinical performance even though longer follow up studies are required. In a multicentre study Gao et al. reported that seven of 156 cases of ACL reconstruction using the LARS ${ }^{\mathrm{TM}}$ ligament were noted to have ligament failure at the bone tunnel with loose screw or loose graft within three to five years [35]. Instead of the fibrocartilage transitional zone usually found in the native ACL insertion sites, an interposed layer of fibrous scar tissue appeared at the interface between the graft and the bone tunnel after ACL reconstruction using the LARS ${ }^{\mathrm{TM}}$. Long-term motion resulting in poor ligament-tobone integration could possibly lead to graft laxity and failure [18].

The strategy utilised in this present study involved the grafting of a polyNaSS bioactive polymer on the surface of implant to enhance the quality of the bio-integration in the bone tunnels. Even though this surface modification already demonstrated a beneficial effect onto ligament fibroblasts and is known to affect their adhesion strength and permit the formation of a more organised tissue [20], the interaction of this grafting material onto primary human osteoblasts remained unclarified. The in vitro findings presented in this study clearly revealed the positive impact of the polyNaSS grafting onto the performances of human osteoblasts. The enhanced cellular response resulted in higher levels of ALP expression and mineralisation which were in accordance with previous studies displaying similar results, albeit for an osteoblastic cell line (MG63 [20,21]). In addition, $24 \mathrm{~h}$ post seeding, the number of osteoblasts proliferating onto the grafted structures was still significantly higher which indicates that the surface modification 
a

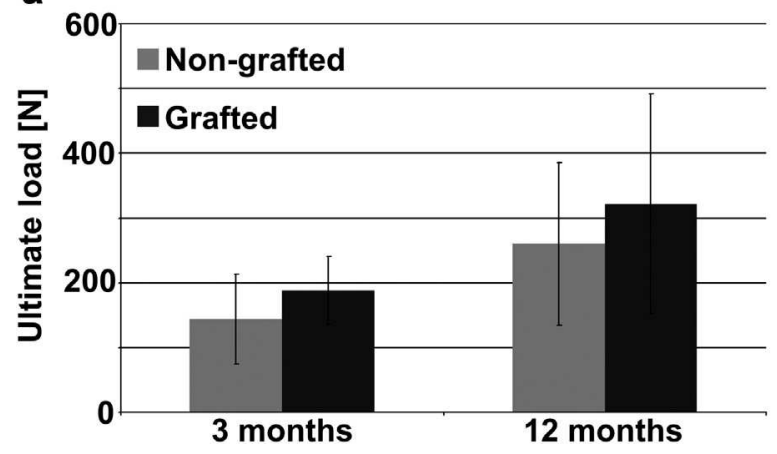

b

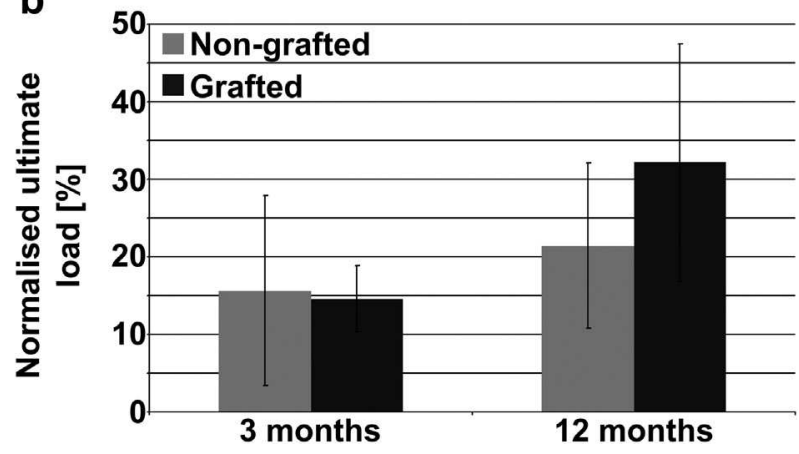

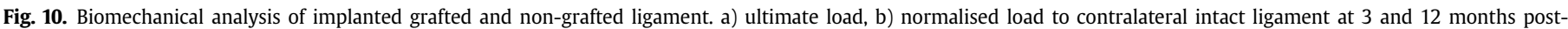
implantation.

had an important influence over cell adhesion as it has been previously reported for several cell types $[20,21]$. Regardless of the coating, the structures experienced a gradual decrease in the DNA content and cells did not infiltrate nor survive deeply within the structure, pointing out that diffusion of oxygen and nutrient supply were sub-optimal. This in vitro observation should be examined in the light of the in vivo experiments, which showed entire cell colonisation three months post implantation in our ovine model. Similar observation was reported in human six month post-surgery in an explanted artificial LARS ligament [36]. Even though, the cells were not capable of infiltrating the ligaments in vitro, the in vivo response completely differed and full colonisation was achieved at the central core of the ligaments 3 months post-surgery. Despite what may appear as adequate tissue colonisation, the architecture of the bone compartment could be revised and improved by assembling the polymer filaments in a less dense manner to further facilitate cell and tissue infiltration. This should theoretically result in better anchorage and integration of the implant into the surrounding bone. Indeed larger pore size, typically above $100 \mu \mathrm{m}$ is generally associated with appropriate bone ingrowth and vascularisation, essential for osteogenesis and bone remodelling [37]. It is worth noting that even though the amount of bone in the ligament was equivalent for both non-grafted and grafted specimen throughout the experiment, higher occurrence of bone formation in the grafted specimens was found at 12 months postimplantation. This suggests that the polyNASS grafting was capable of initiating bone formation, which would later on colonise the centre of the ligament in a more predictable manner and hence enhance the ligament integration. This is of particular relevance as tunnel osteolysis is generally associated with the utilisation of synthetic ligaments and is considered as a crucial parameter for ligament biomechanical stability. Indeed, in the early nineties Seemann et al. observed osteolytic widening of the tibial tunnels during revision surgeries [38] and this was confirmed by other studies as a common issue found in clinical situations $[39,40]$. Fukubayashi performed a 5-11 year follow-up study of Gore-Tex anterior cruciate ligament and reported that most of the nonruptured implants resulted in tunnel widening [39]. Muren et al. confirmed this more recently in their 13-15 year follow-up study whereby tunnel widening occurred in 15 of their 17 patients [40]. In the present study, the acute degradation of the surrounding bone was not observed at either 3 or 12 months post-implantation, however a significant increase in the area occupied by the fibrous tissue was observed for the non-grafted ligaments and the occurrence of bone formation in the core of the implants, initially at $33 \%$ dropped to $20 \%$ suggesting that early stage osteolysis was observed in the NGL group. The opposite trend was observed for the grafted specimens, that is, thinner connective tissue, higher occurrence of bone formation within the ligament and higher total length of ligament to bone contact at 12 months post-implantation.

Another aspect highlighting the importance of enhancing bone formation around and within the artificial ligament, is related to the ligament anchorage into the bone tunnels which strongly affect the ligament biomechanical stability but also has implication in the reduction or elimination of wear particles during the implant life time [18]. It is generally recommended that the artificial ligament is positioned through the remaining ruptured ACL in order to facilitate fibrovascular tissue ingrowths which will protect the ligament from excessive damage and wear (induced by the surrounding hard tissues) and prevent the release of potential wear particles in the joint cavity [16]. Apart from the protection provided by soft tissue colonisation or remaining thereof, it is crucial that the artificial ligament enables rapid bone ingrowths to prevent or further reduce wear occurring at the extremities of the bone tunnels. Indeed, failure and wear mechanism in artificial prosthesis are often initiated at the bone-ligament interface as polymeric fibres are repetitively contact-damaged by the surrounding hard tissues [41-43]. To this end, we demonstrated the

Table 4

Failure mode for the pull-out tests and pre-existing partial failure of the synthetic ligament (if any).

\begin{tabular}{|c|c|c|c|c|c|c|c|c|}
\hline & \multicolumn{4}{|c|}{3 months implantation } & \multicolumn{4}{|c|}{12 months implantation } \\
\hline & Contro-lateral & GL & Contro-lateral & NGL & Contro-lateral & GL & Contro-lateral & NGL \\
\hline Femoral slippage & $0 / 7$ & $3 / 7$ & $0 / 5$ & $1 / 5$ & $0 / 8$ & $1 / 8$ & $0 / 7$ & $0 / 7$ \\
\hline With existing partial failure & & $33 \%$ & & $0 \%$ & & $0 \%$ & & $0 \%$ \\
\hline Tibial slippage & $0 / 7$ & $1 / 7$ & $0 / 5$ & $1 / 5$ & $0 / 8$ & $2 / 8$ & $0 / 7$ & $2 / 7$ \\
\hline With existing partial failure & & $0 \%$ & & $0 \%$ & & $0 \%$ & & $0 \%$ \\
\hline Ligament failure & $1 / 7$ & $3 / 7$ & $2 / 5$ & $3 / 5$ & $6 / 8$ & $5 / 8$ & $5 / 7$ & $5 / 7$ \\
\hline With existing partial failure & & $33 \%$ & & $67 \%$ & & $40 \%$ & & $60 \%$ \\
\hline Osteocartilaginous avulsion & $5 / 7$ & $0 / 7$ & $2 / 5$ & $0 / 5$ & $2 / 8$ & $0 / 8$ & $2 / 7$ & $0 / 7$ \\
\hline Other & $1 / 7$ & $0 / 7$ & $1 / 5$ & $0 / 5$ & $0 / 8$ & $0 / 8$ & $0 / 7$ & $0 / 7$ \\
\hline
\end{tabular}


utility of grafting procedure as the grafted samples displayed better bio-integration since more frequent ligament-to-bone contact was observed at all time points. Interestingly, the incidence of wear (which in our study was observed in the close vicinity of the tunnel openings) tended to be lower in grafted ligaments compared to non-grafted ligaments (8/29 versus $12 / 25$, respectively). Other strategies involving filling of the bone tunnel with osteoconductive cement [44-47], surface modification of natural or artificial grafts $[18,48,49]$ have been developed in the past in an effort to enhance the healing at the bone-ligament interface. Several studies utilised biphasic calcium phosphate cement for implementing the bone healing and the insertion of natural implants (semitendinosus tendon [45,46], long digital extensor tendon [44,47]) into the surrounding tissues [45-47]. These techniques demonstrated interesting results in animal models such as rabbits and dogs and showed that the healing of the bone-ligament interface was significantly enhanced when a calcium phosphate cement was used. This was characterised by higher ultimate pull-out loads within the cemented implanted ligament groups, and histology analysis confirmed the earlier integration of the natural implant into the surrounding bone as seen per the presence of Sharpey's fibres inserting into both soft and hard tissue. Even though this strategy was proven efficient for the purpose of enhancing tissue integration, there are a number of concerns which have not been addressed. Indeed, the pull-out strengths measured in these studies were still well below of that of relevant in human. The application of such cements should be performed in very controlled manner in order to avoid dispersion of the mineralised particles upon contact with physiological fluids. Also the extra time required for the cement to set could contribute in increasing the length of the surgical procedure and therefore its cost.

Previous studies directly deposited a biomimetic calcium phosphate mineral layer onto the graft or artificial ligament $[18,48,49]$. Mutsuzaki et al. coated a calcium phosphate layer onto the extremities of an autologous graft (flexor digitorum longus tendon and hamstring tendon) via a series of successive immersion in solutions containing phosphate or calcium ions [48-51]. This method permitted the formation of a low crystallinity apatite which was proposed to be responsible for a firmer anchorage of the graft in the bone tunnels [50]. The outcomes of this procedure have been documented for ACL reconstruction in rabbit and goat and these studies demonstrated that the CaP-hybridised tendon promoted histologically verified bone to graft insertion although no clear biomechanical differences in pull-out loads were found [49,50]. A similar strategy has also been developed by Li et al. [18] for the LARS artificial ligament. In this recent study, LARS ${ }^{\mathrm{TM}}$ bone compartment was surface modified by immersing the PET fibres for $2 \mathrm{~h}$ into a gelatine solution containing dispersed nano-hydroxyapatite particles. This surface modified ligament was further implanted using an extra-articular graft to bone healing model in rabbit and showed superior performances 8 weeks post-implantation in a pull-out biomechanical testing. Although these studies, utilising different techniques, indicated beneficial effect of the modified grafts and implants, a number of technical factors remain unaddressed such as the reproducibility, homogeneity and adhesion and stability over time of the coating. Indeed, Chim et al. reported the detachment of a biomimetic calcium phosphate coating from their polycaprolactone fused deposition modelling scaffolds when cultured in vitro for 3 weeks [52]. This was caused by the forces exerted on to the coating by the cells and if similar event would occur in vivo it would be detrimental to the ligament-to-bone insertion. The method utilised to surface modify the PET fibres with PolyNASS ensures that the grafting materials is covalently bound to the polymer resulting in its excellent stability which will permit appropriate tissue integration.
In the present study, grafting of the LARS ${ }^{\mathrm{TM}}$ had no adverse impact on the biomechanical behaviour of reconstructed stifles. In $75 \%$ of the specimens explanted 3 months postoperatively tested in the present study, mechanical failure in tension of ligament reconstruction occurred by slippage of the artificial ligament from either the femoral or the tibial tunnels with no differences between GL and NGL. Although tension loading was performed in line with the long axis of the bone tunnels (which represents the worst case scenario), these observations suggest the fact that 3 months post-operatively, artificial ligament-bone interface remains a weak link. This finding is in accordance with a previous study in humans which showed that fixation is a weak link early in the rehabilitation process [53]. Loading direction in our study was performed in line with the interference screws thus simulating a "worst-case scenario". Such experimental design allowed testing of ligament-to-bone fixation and of the intra-articular portion of the ligament, failure occurring at the level of the weakest part of the reconstruction. Thus, in worn ligaments, failure occurred at the level of the intracapsular, ruptured fibres. In these cases, load failure values did not reflect the biomechanical properties of the ligament-to-bone interface. The incidence of failure through slippage of the ligament through the bone tunnels decreased to $50 \%$ from 3 to 12 months for both GL and NGL. This observation provided evidence that the mechanical strength of the bone anchorage improved over time. However, significant impact of grafting on the biomechanical characteristics of ligament-to-bone insertion in vivo could not be established in the present study at both time points even though histologically verified higher direct ligament-bone contacts were observed for polyNaSS grafted ligaments. Despite strong histological evidences of enhanced ligament-to-bone insertion, Mutzusaki et al. did not observe a significant biomechanical improvement when performing pull out tests $[49,50]$ similarly to the present study. Another recent study by these authors revealed that even though the pull out loads were similar for their CaP-hybridised tendon and control tendons, the in situ force in response to an anteroposterior tibial load of $50 \mathrm{~N}$ was close to that of intact ligament whereas the control graft reach only $50 \%$ of this value at 1 year post-implantation in a goat model [48]. This indicates that enhanced integration in the bone tunnel might not necessarily translate into higher pull out load but may have other beneficial implications in the global biomechanical behaviour of the ligament.

\section{Conclusion}

This study has shown the beneficial effect of PolyNaSS grafting onto the LARS ${ }^{\mathrm{TM}}$ both in vitro and in vivo. We have demonstrated that the grafting enhanced ALP secretion in osteoblasts and had a significant impact on their in vitro mineralisation as mineralised nodules were detected at the surface of the artificial ligament 6 weeks post seeding under osteogenic induction. We also demonstrated that this effect was translated in vivo into an enhanced direct ligament-to bone contact and decreased fibrous scar tissue at the interface bone/ligament interface 12 months post implantation in an ovine ACL reconstruction model. Taken together the results presented in this study provide evidence that PolyNaSS grafting of PET ligaments, improves artificial ligament osseo-integration within the bone tunnels.

\section{Disclosure statement}

The authors confirm that there are no known conflicts of interest associated with this publication and there has been no significant financial support for this work that could have influenced its outcome. 


\section{Acknowledgements}

This research has funded by the French National Research Agency (program Ligart ANR) and French Ministry of Research. The authors would like to thanks Mr Bernard Brulez from LARS SA for kindly providing the artificial ligaments utilised in this study. The authors are gratefully to Dr Christina Theodoropoulos for proofreading the manuscript. The XPS experiments were done at the National ESCA and Surface Analysis Center for Biomedical Problems, which is supported by grant EB-002027 from the United States Institutes of Health.

\section{References}

[1] Duthon VB, Barea C, Abrassart S, Fasel JH, Fritschy D, Ménétrey J. Anatomy of the anterior cruciate ligament. Knee Surg Sport Traumatol Arthrose 2006;14: 203-13.

[2] Zantop T, Peterson W, Sekiya JK, Musahl V, Fu FH. Anterior cruciate ligament anatomy and function relating to anatomical reconstruction. Knee Surg Sports Traumatol Arthrose 2006;14:982-92.

[3] Kärtus J, Movin T, Karlsson J. Donor-site morbidity and anterior knee problems after anterior cruciate ligament reconstruction using autografts. Arthroscopy: J Arthrosc Rel Surg 2001;17:971-80.

[4] Olson EJ, Kang JD, Fu FH, Georgescu HI, Mason GC, Evans CH. The biochemical and histological effects of artificial ligament wear particles: in vitro and in vivo studies. Am J Sports Med 1988;16:558-70.

[5] Paulos LE, Rosenberg TD, Grewe SR, Tearse DS, Beck CL. The Gore-tex anterior cruciate ligament prosthesis: a long term followup. Am J Sports Med 1992;20: 246-52.

[6] Alm A, Gillquist J. Reconstruction of the anterior cruciate ligament by using the medial third of the patellar ligament: treatment and results. Acta Chir Scand 1974;140:289-96.

[7] Sajovic M, Strahovnik A, Dernovsek MZ, Skaza K. Quality of life and clinical outcome comparison of semitendinosus and gracilis tendon versus patellar tendon autografts for anterior cruciate ligament reconstruction: an 11-year follow-up of a randomized controlled trial. Am J Sports Med 2011;39:2161-9.

[8] Lebel B, Hulet C, Galaud B, Burdin G, Locker B, Vielpeau C. Arthroscopic reconstruction of the anterior cruciate ligament using bone-patellar tendonbone autograft: a minimum 10-year follow-up. Am J Sports Med 2008;36: $1275-82$.

[9] Wipfler B, Donner S, Zechmann CM, Springer J, Siebold R, Paessler HH. Anterior cruciate ligament reconstruction using patellar tendon versus hamstring tendon: a prospective comparative study with 9-year follow-up. Arthroscopy: J Arthrosc Rel Surg 2011;27:653-65.

[10] Lidén M, Sernert N, Rostgård-Christensen L, Kartus C, Ejerhed L. Osteoarthritic changes after anterior cruciate ligament reconstruction using bone-patellar tendon-bone or hamstring tendon autografts: a retrospective, 7-year radiographic and clinical follow-up study. Arthroscopy 2008;24:899-908.

[11] LARS SA. Ligaments: dimensional characteristics. Tech Brochure 2012 18/01/ 2012.

[12] Lavoie P, Fletcher J, Duval N. Patient satisfaction needs as related to knee stability and objective findings after ACL reconstruction using the LARS artificial ligament. Knee 2000;7:157-63.

[13] Machotka Z, Scarborough I, Duncan W, Kumar S, Perraton L. Anterior cruciate ligament repair with LARS (ligament advanced reinforcement system): a systematic review. Sports Med Arthrosc Rehabil Ther Technol 2010;2:1-10.

[14] Nau T, Lavoie P, Duval N. A new generation of artificial ligaments in reconstruction of the anterior cruciate ligament: two-year follow-up of a randomised trial. J Bone Jt Surg Br 2002;84:356-60.

[15] Shen G, Xu Y, Dong Q, Zhou H, Yu C. Arthroscopic posterior cruciate ligament reconstruction using LARS artificial ligament: a retrospective study. J Surg Res 2012;173:75-82.

[16] Glezos CM, Waller A, Bourke HE, Salmon LJ, Pinczewski LA. Disabling synovitis associated with LARS artificial ligament use in anterior cruciate ligament reconstruction: a case report. Am J Sports Med 2012;40:1167-71.

[17] Li H, Yao Z, Jiang J, Hua Y, Chen J, Li Y, et al. Biologic failure of a ligament advanced reinforcement system artificial ligament in anterior cruciate ligament reconstruction: a report of serious knee synovitis. Arthroscopy: J Arthrosc Rel Surg 2012;28:583-6.

[18] Li H, Ge Y, Wu Y, Jiang J, Gao K, Zhang P, et al. Hydroxyapatite coating enhances polyethylene terephthalate artificial ligament graft osseointegration in the bone tunnel. Inter Orthop (SICOT) 2011;35:1561-7.

[19] Ciobanu M, Siove A, Gueguen V, Gamble LJ, Castner DG, Migonney V. Radical graft polymerization of styrene sulfonate on poly(ethylene terephthalate) films for ACL applications: "grafting from" and chemical characterization. Biomacromolecules 2006; 7:755-60.

[20] Pavon-Djavid G, Gamble LJ, Ciobanu M, Gueguen V, Castner DG, Migonney V. Bioactive poly(ethylene terephthalate) fibers and fabrics: grafting, chemical characterization, and biological assessment. Biomacromolecules 2007;8: 3317-25.
[21] Hélary G, Noirclère F, Maying J, Bacroix B, Migonney V. A bioactive polymer grafted on titanium oxide layer obtained by electrochemical oxidation. Improvement of cell response. J Mater Sci Mater Med 2010;21:655-63.

[22] Hélary G, Noirclère F, Maying J, Migonney V. A new approach to graft bioactive polymer on titanium implants: improvement of MG 63 cell differentiation onto this coating. Acta Biomater 2009;5:124-33.

[23] Michiardi A, Hélary G, Nguyen P-CT, Gamble LJ, Anagnostou F, Castner DG, et al. Bioactive polymer grafting onto titanium alloy surfaces. Acta Biomater 2010;6:667-75.

[24] Kerner S, Migonney V, Pavon-Djavid G, Hélary G, Sedel L, Anagnostou F. Bone tissue response to titanium implant surfaces modified with carboxylate and sulfonate groups. J Mater Sci Mater Med 2010;21:707-15.

[25] Altman GH, Horan RL, Lu HH, Moreau J, Martin I, Richmond JC, et al. Silk matrix for tissue engineered anterior cruciate ligaments. Biomaterials 2002;23:4131-41.

26] Goh JC-H, Ouyang $\mathrm{H}-\mathrm{W}$, Teo $\mathrm{S}-\mathrm{H}$, Chan $\mathrm{CKC}$, Lee E-H. Tissue engineering approach to the repair and regeneration of tendons and ligaments. Tissue Eng 2003;9:S31-44.

[27] Laurencin CT, Freeman JW. Ligament tissue engineering: an evolutionary materials science approach. Biomaterials 2005;26:7530-6.

[28] Ouyang H-W, Goh JC-H, Thambyah A, Teoh SH, Lee EH. Knitted polylactide-coglycolide scaffold loaded with bone marrow stromal cells in repair and regeneration of rabbit Achilles tendon. Tissue Eng 2003;9:431-9.

[29] Ouyang H-W, Lok SL, Goh J, Tay TE, Moe K. Assembly of bone marrow stromal cell sheets with knitted poly(L-lactide) scaffold for engineering ligament analogs. J Biomed Mater Res B Appl Biomater 2005;75:264-71.

[30] Sahoo S, Ouyang H, Goh JCH, Tay TE, Toh SL. Characterization of a nove polymeric scaffold for potential application in tendon/ligament tissue engineering. Tissue Eng 2006 Jan;12(1):91-9.

[31] Sahoo S, Toh SL, Goh JCH. A bFGF-releasing silk/PLGA-based biohybrid scaffold for ligament/tendon tissue engineering using mesenchymal progenitor cells. Biomaterials 2010 Apr;31(11):2990-8.

[32] Vaquette C, Kahn C, Frochot C, Nouvel C, Six JL, De Isla N, et al. Aligned poly(Llactic-co-e-caprolactone) electrospun microfibers and knitted structure: a novel composite scaffold for ligament tissue engineering. J Biomed Mater Res A 2010 Sep;94A(4):1270-82.

[33] Vaquette C, Slimani S, Kahn CJ-F, Tran N, Rahouadj R, Wang X. A poly(lacticco-glycolic acid) knitted scaffold for tendon tissue engineering: an in vitro and in vivo study. J Biomat Sci Polym Edn 2010;21:1737-60.

[34] Cao D, Liu W, Wei X, Xu F, Cui L, Cao Y. In vitro tendon engineering with avian tenocytes and polyglycolic acids: a preliminary report. Tissue Eng 2006;12: 1369-77.

[35] Gao K, Chen S, Wang L, Zhang W, Kang Y, Dong Q et al. Anterior cruciate ligament reconstruction with LARS artificial ligament: a multicenter study with 3- to 5-year follow-up. Arthroscopy 2010;26:515-23.

[36] Trieb K, Bladovec H, Brand G, Sabeti M, Dominkus M, Kotz R. In vivo and in vitro cellular ingrowth into a new generation of artificial ligaments. Eur Surg Res 2004;36:148-51.

[37] Karageorgiou V, Kaplan D. Porosity of 3D biomaterial scaffolds and osteogenesis. Biomaterials 2005;26:5474-91.

[38] Seemann MD, Steadman JR. Tibial osteolysis associated with Gore-Tex grafts. Am J Knee Surg 1993;6:31-8.

[39] Fukubayashi T, Ikeda K. Follow-up study of Gore-Tex artificial ligamentspecial emphasis on tunnel osteolysis. J Long Term Eff Med Implants 2000;10: 267-77.

[40] Muren O, Dahlstedt L, Brosjö E, Dahlborn M, Dalén N. Gross osteolytic tibia tunnel widening with the use of Gore-Tex anterior cruciate ligament prosthesis:A radiological, arthrometric and clinical evaluation of 17 patients $13-$ 15 years after surgery. Acta Orthop 2005;76:270-4.

[41] Poddevin N, Cronier B, Marois Y, Delagoutte JP, Mainard D, Jaeger JH, et al Macroscopic, histologic and ultrastructural study of 89 prostheses of anterior cruciate ligament excised because of prosthesis failure. Rev Chir Orthop 1995;81:410-8.

[42] Poddevin N, King MW, Guidoin RG. Failure mechanisms of anterior cruciate ligament prostheses: in vitro wear study. J Biomed Mater Res B Appl Biomater 1997; 38:370-81

[43] Guidoin M-F, Marois Y, Bejui J, Poddevin N, King MW, Guidoin R. Analysis of retrieved polymer fiber based replacements for the ACL. Biomaterials 2000;21:2461-74.

[44] Huangfu X, Zhao J. Tendon-bone healing enhancement using injectable tricalcium phosphate in a dog anterior cruciate ligament reconstruction model. Arthroscopy: J Arthrosc Rel Surg 2007;23:455-62.

[45] Shen H, Qiao G, Cao H, Jiang Y. An histological study of the influence of osteoinductive calcium phosphate ceramics on tendon healing pattern in a bone tunnel with suspensory fixation. Inter Orthop (SICOT) 2010;34 917-24.

[46] Tien Y-C, Chih T-T, Lin J-HC, Ju C-P, Lin S-D. Augmentation of tendon-bone healing by the use of calcium-phosphate cement. J Bone Jt Surg Br 2004;86B:1072-6.

[47] Wen C-Y, Qin L, Lee K-M, Chan K-M. The use of brushite calcium phosphate cement for enhancement of bone-tendon integration in an anterior cruciate ligament reconstruction rabbit model. J Biomed Mater Res B Appl Biomater 2009;89B:466-74.

[48] Mutsuzaki H, Sakane M, Fujie H, Hattori S, Kobayashi H, Ochiai N. Effect of calcium phosphate-hybridized tendon graft on biomechanical behavior in 
cruciate ligament reconstruction in a goat model: novel technique for improving tendon-bone healing. Am J Sports Med 2011;39:1059-66.

[49] Mutsuzaki H, Sakane M, Nakajima H, Ochiai N. Calcium phosphate-hybridised tendon graft to reduce bone-tunnel enlargement after ACL reconstruction in goats. Knee 2012;19:455-60.

[50] Mutsuzaki H, Sakane M, Hattori S, Kobayashi H, Ochiai N. Firm anchoring between a calcium phosphate-hybridized tendon and bone for anterior cruciate ligament reconstruction in a goat model. Biomed Mater 2009;4:045013.
[51] Mutsuzaki H, Sakane M, Nakajima H, Ito A, Hattori S, Miyanaga Y, et al. Calcium-phosphate-hybridized tendon directly promotes regeneration of tendon-bone insertion. J Biomed Mater Res A 2004;70:319-27.

[52] Chim H, Hutmacher DW, Chou AM, Oliveira AL, Reis RL, Lim TC, et al. A comparative analysis of scaffold material modifications for load-bearing applications in bone tissue engineering. Int J Oral Maxillofac Surg 2006;35:928-34.

[53] Chen NC, Brand JCJ, Brown CHJ. Biomechanics of intratunnel anterior cruciate ligament graft fixation. Clin Sports Med 2007;26:695-714. 